\title{
Analysis on Characteristics of Surrounding Rocks of Roadway and Bearing Structure Based on Stress Regulation
}

\author{
Ruofei Zhang, ${ }^{1,2}$ Guangming Zhao $\mathbb{D}^{1,2}$ Xiangrui Meng, ${ }^{1,2}$ Jian Sun, ${ }^{1,2}$ Wensong Xu $\mathbb{D}^{1,2}$ \\ Yingming $\mathrm{Li} \mathbb{1}{ }^{1,2}$ Zenghui Liu, ${ }^{1,2}$ and Siming Kao $\mathbb{D}^{1,2}$ \\ ${ }^{1}$ State Key Laboratory of Mining Response and Disaster Prevention and Control in Deep Coal Mines, \\ Anhui University of Science and Technology, Huainan 232001, China \\ ${ }^{2}$ School of Mining Engineering, Anhui University of Science and Technology, Huainan 232001, China
}

Correspondence should be addressed to Guangming Zhao; guangmingzhao@163.com

Received 24 December 2020; Accepted 10 March 2021; Published 22 March 2021

Academic Editor: Zhijie Wen

Copyright ( $(2021$ Ruofei Zhang et al. This is an open access article distributed under the Creative Commons Attribution License, which permits unrestricted use, distribution, and reproduction in any medium, provided the original work is properly cited.

To address the prominent status of great deformation and difficult maintenance of the roadway under high stresses, this study investigated the mechanical characteristics of surrounding rocks and bearing structural stability in a roadway under adjustment and redistribution of stresses through theoretical analysis, numerical simulation, and engineering field test. Stability forms of the bearing structure of roadway surrounding rocks were analyzed by using the axis-changing theory from the perspectives of surrounding rock, mechanical properties of roadways, surrounding rock stress distribution, and mechanical mechanism of the bearing structure. It is suggested that the surrounding rock stress distribution state is improved and the bearing structure is optimized through unloading and reinforcement construction. A mechanical model of roadway excavation was constructed to analyze the influences of excavation spatial effect on the stress releasing and bearing structure of surrounding rocks. A rock postpeak strain softening and dilatation model was introduced to investigate the mechanical characteristics of the surrounding rock mass in the rupture residual zone and plastic softening zone in a roadway. Moreover, we analyzed the influences of unloading and reinforcement construction on the stress path and mechanical characteristics of the rock unit model, which disclosed the adjustment mechanism of the bearing structure of surrounding rocks by the failure development status of rocks. A numerical simulation on the distribution of surrounding rock stress fields and adjustment features of the bearing structure after roadway excavation and unloading and reinforcement construction was carried out by using the FLAC ${ }^{3 \mathrm{D}}$ program. Results demonstrate that the unloading construction optimizes the axial ratio of spatial excavation in a roadway and the reinforcement zones on both sides are the supporting zones of the bearing structure. Moreover, the ratio between the distance from two side peaks to the roadway sides and the distance from the roof and floor peaks to the excavation space is equal to the coefficient of horizontal pressure. In other words, the final collapse failure mode of surrounding rock is that the long axis of the excavation unloading space points to the same direction with the maximum principal stress of the primary rock. Reinforcement forces the surrounding rocks to form a " $\Omega$-shaped" bearing structure, which is in favor of the long-term maintenance of the roadway.

\section{Introduction}

Currently, the mining intensity of coal mines is increased, and the mining depth increases continuously due to the increasing exhaustion of shallow resources. New common problems, including worsening geological conditions, increasing fractured rock masses, and increasing geostress, become increasingly prominent [1]. Moreover, the surrounding rocks in a high-stress roadway present evident strain softening and dilatation features after peak [2-4]. Intensity of rock mass declines, accompanied by serious convergence deformation and continuous creeping of surrounding rocks. The bearing structure of the roadway surrounding rock is out of accordance with the high-stress distribution, thus lowering the bearing capacity of the surrounding rock. Stability control of surrounding rocks in a high-stress roadway is still a weak link in roadway support [5]. 
A lot of studies on surrounding rock stress distribution in a high-stress roadway and bearing structural stability control of surrounding rocks, which have achieved many theoretical results, have been carried out [6-9]. The most representative one is the new Austrian tunneling method proposed by L. V. Rabcewice. The core idea of this new Austrian tunneling method is to maintain the inherent strength of surrounding rock to the maximum extent, make full use of the bearing capacity of surrounding rock, and promote the surrounding rock to serve as an important component of the support structure [10]. According to the theory of loose circle supporting for roadway surrounding rocks proposed by Dong et al. [11], the support structure is to restrict the harmful deformation caused by intermediate crushing in the development process of the loose circle on surrounding rocks. Moreover, size of the loose circle is determined by the mutual interaction between the surrounding rock stresses and the intensity of rock masses, and the excessive expansion of broken cracks is restricted through collapse prevention based on the meshing of broken rock masses [12]. According to the key circle theory of roadway surrounding rocks proposed by Kang et al. [13], the stability of the roadway is determined by the key bearing layer which undertakes a relatively large tangential stress, and the stress distribution state can be changed through various artificial stress control measures $[14,15]$. The joint supporting technology based on the new Austrian tunneling method believes that a complicated highstress roadway only considers that increasing the supporting intensity of surrounding rock is difficult to achieve the expected effect and the supporting principle shall observe the principle of "flexible first and then rigid, resistance-yieldresistance, appropriate flexibility and yield, yield-resistance combination and stable support." The axis-changing theory proposed by $\mathrm{Yu}$ and Qiao $[16,17]$ believes that surrounding rock failure in a roadway is caused by excessive stresses over the strength limit of rock mass and the axial ratio for roadway excavation is changed due to the collapse and deformation of surrounding rock, thus triggering stress redistribution of surrounding rock until realizing stable collapse of broken surrounding rocks [18]. Li et al. [19] proposed an "internalexternal" bearing structure that explains the influences of "spatial effect." Fang [20] believed that the mechanical forms of deep surrounding rocks present tensile compressive strain alternations and "compression and stretching" are the mechanism to form a loose circle with surrounding rock. The concept of the collaborative effect of "primary-secondary" bearing zones was also proposed. Hou [21] studied the influences of the spatial effect of excavation surface on surrounding rock deformation. He pointed out that roadway extraction is indeed a transformation from the stress state of primary rock into the stress state of surrounding rock after excavation. Zuo et al. [22] analyzed the control over surrounding rock deformation by slotting and unloading in a deep soft rock roadway. Zhao et al. [23] divided the bearing structure of roadway surrounding rocks into deep (shallow) supporting layers and introduced their evolutionary features into the surrounding rock stability control of a roadway.

To sum up, research on the redistribution of surrounding rock stress and bearing mechanism of surrounding rocks after roadway excavation has achieved many results. Bearing structure is the main carrier of surrounding rock stresses. Controlling the distribution of stresses and bearing structural stability have positive effects on roadway maintenance, which have been widely accepted. Nevertheless, further studies on surrounding rock mechanical properties and bearing structural stability in a roadway under the initiative controllable adjustment of stresses are still needed.

In this study, the mechanical features of surrounding rocks and the mechanical mechanism of the bearing structure under surrounding rock stress adjustment in a roadway were discussed. Based on the spatial effect theory, uniform strength criteria, and nonassociated flow rule, a postpeak strain softening and dilatation model was introduced, which theoretically disclosed the control mechanism of unloading and reinforcement construction over the stress distribution state and deformation characteristics of surrounding rocks on the free face. We investigated the deformation mechanism of postpeak rock failure development under the influences of softening, bulking, and dilatation deformation of surrounding rocks. Besides, the bearing structural adjustment mechanism through the failure development state of rocks was disclosed. Moreover, such adjustment mechanism was verified through a numerical calculation and field application effect. This study has important references to surrounding rock control in a highstress roadway which is difficult to be supported.

\section{Surrounding Rock Stability and Control Mechanism in a Roadway}

2.1. Bearing Structural Stability Forms of Roadway Surrounding Rocks. Roadway excavation and unloading destroy the original geostress balance, thus resulting in redistribution of surrounding rock stress. When stress on surrounding rocks at a local position of free face exceeds the strength limit, surrounding rocks develop failure deformations. Axial ratio of free face changes during the progressive failure development. Meanwhile, the strong and weak bearing structures are adjusted gradually, and the failure evolution process stops if stresses on a deep boundary $\left(r=l_{0}\right)$ are controlled within the strength limit of the surrounding rocks. In this case, axial ratio on the equivalent free face after surrounding rock fracture in a roadway is the optimal axial ratio under such stress conditions. Due to different mechanical properties and stress distribution states, surrounding rocks are adjusted, forming a closed stable state. This is conducive to developing the self-bearing capacity to the maximum extent and improving coordination of surrounding rocks to the stress environment. Unloading and reinforcement construction was proposed according to the axis-changing theory to control the bearing structural stability based on stress control. In other words, the axial ratio of an equivalent free face in a roadway is controlled positively to promote the bearing structure adapting to the distribution state of surrounding rock stresses.

According to analysis of bearing structural stability forms of surrounding rocks based on axis-changing theory, the final failure mode is manifested by the consistent 
directions between the long axis of excavation unloading space and the maximum principal stress of primary rocks. Under this circumstance, a uniform closed bearing structure is formed, which is the final stable structural form in the surrounding rock failure zone in a roadway. The stress model on the bearing structure in an equivalent roadway excavation spatial effect is shown in Figure 1. According to the axis-changing theory, the tangential stress of surrounding rocks in an equivalent excavation space can be expressed as

$$
\left.\sigma_{\theta}\right|_{r=l_{0}}=\frac{p_{0}}{a-b}\left[\frac{4 a b(a-\lambda b)}{\left(a^{2}+b^{2}\right)-\left(a^{2}-b^{2}\right) \cos 2 \theta}+(a+b)(\lambda-1)\right],
$$

where $l_{0}(m)$ is the distance from the bearing structural boundary of surrounding rocks in an equivalent roadway excavation spatial effect to the center of a roadway. $p_{0}(\mathrm{MPa})$ is the stress of primary rocks. $\lambda$ is the coefficient of horizontal pressure. $a$ and $b$ are radius of the long axis and radius of the short axis of stable structural form (equivalent excavation space) after surrounding rock failure, respectively. In other words, $a(m)$ is the sum of the excavation radius of a roadway $(r)$ and the plastic failure zones which are produced by the unloading scope $(s) . b(m)$ is the radial plastic failure size along the excavation radius $(r)$.

The bearing structure in an equivalent roadway excavation spatial effect is simplified as a stress-bearing oval in the analysis. The axial ratio is $\left.\sigma_{\theta}\right|_{r=l_{0}}=\left(p_{0} / a-b\right)[(4 a b(a-$ $\left.\left.\lambda b) /\left(a^{2}+b^{2}\right)-\left(a^{2}-b^{2}\right) \cos 2 \theta\right)+(a+b)(\lambda-1)\right], \quad(g>0$ $g=a / b$ and $g \neq 1$ ). The $a=g b$ was brought into (1) and it can get

$$
\left.\sigma_{\theta}\right|_{r=l_{0}}=\frac{p_{0}}{(g-1)}\left[\frac{4 g(g-\lambda)}{\left(g^{2}+1\right)-\left(g^{2}-1\right) \cos 2 \theta}+(g+1)(\lambda-1)\right] .
$$

Equation (2) was analyzed as a function of $\sigma_{\theta}$ about $\theta$ $(0 \leq \theta \leq 2 \pi)$. Through derivation of $\sigma_{\theta}$ about $\theta$, it can be seen that $\theta=0, \pi / 2, \pi$, and $3 \pi / 2$ are extreme points. Next, $\theta=0, \pi$, $\pi / 2$, and $3 \pi / 2$ were brought into (1), thus getting tangential stresses at the end points of vertical axis and horizontal axis of final failure stability structural forms of surrounding rocks. Moreover, variations of these two tangential stresses are corresponding. One pair is the maximum, and the other pair is the minimum.

$$
\left\{\begin{array}{l}
\sigma_{\theta v(\perp)}=\left[\left(\frac{2 b}{a}+1\right) \lambda-1\right] p_{0}, \\
\sigma_{\theta h(-)}=\left(\frac{2 a}{b}-\lambda+1\right) p_{0} .
\end{array}\right.
$$

In (3), let $\sigma_{\theta v(\perp)}=\sigma_{\theta h(-)}$ and it can calculate

$$
\begin{aligned}
g & =\lambda=\frac{a}{b} \\
\sigma_{\theta \nu(\perp)} & =\sigma_{\theta h(-)}\left(\frac{a}{b}+1\right) p_{0}=(g+1) p_{0} .
\end{aligned}
$$

Based on this analysis, it can be known that tangential stresses on the bearing structural boundary of surrounding rocks $\left(r=l_{0}\right)$ in an equivalent roadway excavation spatial effect are equal when $g=\lambda=a / b$ and surrounding rocks are compressed. In addition, let $\sigma_{\theta v(\perp)}=0$ and it can get $\lambda=(g / 2+g)=(a / a+2 b)$. Let $\sigma_{\theta h(-)}=0$, and it can be known that $\lambda=2 g+1=2 a+b / b$. In this case, the equivalent bearing structural boundary $\left(r=l_{0}\right)$ undertakes zero stress.

Hence, stresses on roadway surrounding rocks shall be decreased to the maximum extent, and tensile stress shall be prevented during stress control. Based on the above theoretical analysis, unloading and reinforcement construction is adopted positively to interfere and optimize axial ratio of the equivalent bearing structure and change the transmission path of surrounding rock stresses in the free face by combining practical production conditions in a roadway, aiming to form a closed transmission path of stress in a roadway which is appropriate for surrounding rock reinforcement. As a result, tangential stress distribution on equivalent bearing structure of roadway surrounding rocks is uniform, without tensile stress. This accelerates adjustment of surrounding rocks toward the stable bearing structure and increases selfbearing capacity, thus realizing the goal of long-term stability in a high-stress roadway.

\subsection{Distribution Characteristics of Surrounding Rock Stress} and Bearing Structures in a Roadway. In the following text, influences of initiative construction control over surrounding rock stress distribution on evolutionary characteristics of mechanical properties and bearing structure were analyzed deeply.

Actually, the excavation process is to eliminate failures of excavating rock masses underground (the rock masses which have to be broken and excavated through construction), thus forming a free face with functions. Specifically, the circumferential stress is the most sensitive to excavation disturbance. As a result, surrounding rocks will develop failure deformation when stress exceeds the strength limit, which causes changes of strong and weak areas in surrounding rocks, further triggering adjustment of bearing structural forms.

Surrounding rock strength characteristics are manifested by a full stress-strain curve of rocks (Figure 2). Obviously, influenced by excavation unloading, the abundant strain energies which are accumulated in surrounding rocks are released gradually, resulting in progressive failure of surrounding rocks. According to failure characteristics, surrounding rocks are divided into different mechanical bearing regions (Figure 3), namely, fracture residual zone, plastic softening zone, elastic zone, and stress zone of primary rocks successively from the free face to deep regions. Mechanical properties of rock masses in different zones are corresponding to the full stress-strain curves $(\sigma-\varepsilon)$, and they reflect different failure states. Surrounding rocks in the tangential stress concentration zone $\left(k p_{0} \sim k_{2} p_{0}\right)$ undertake the main loads. In this zone, the main bearing structure is mainly composed of rock masses in the partial plastic zone 


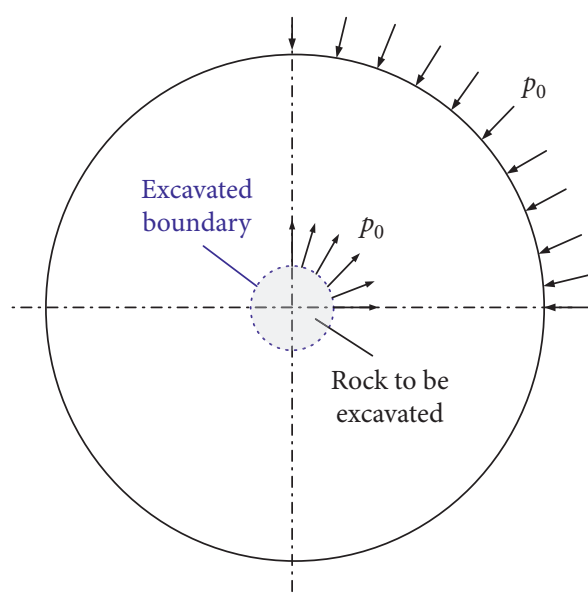

(a)

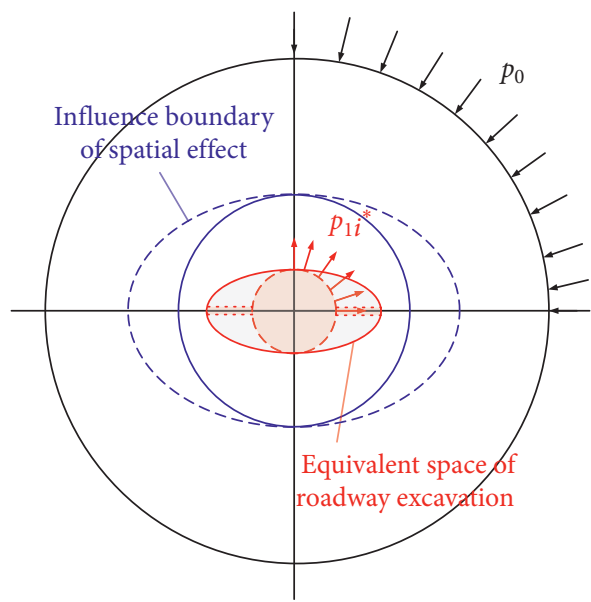

(c)

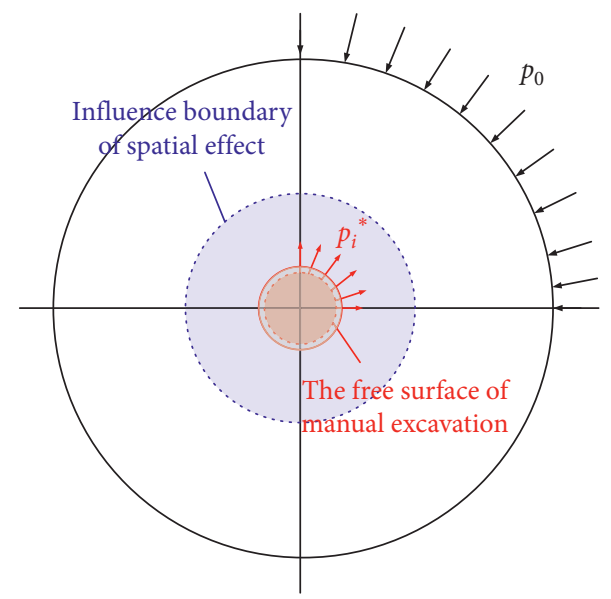

(b)

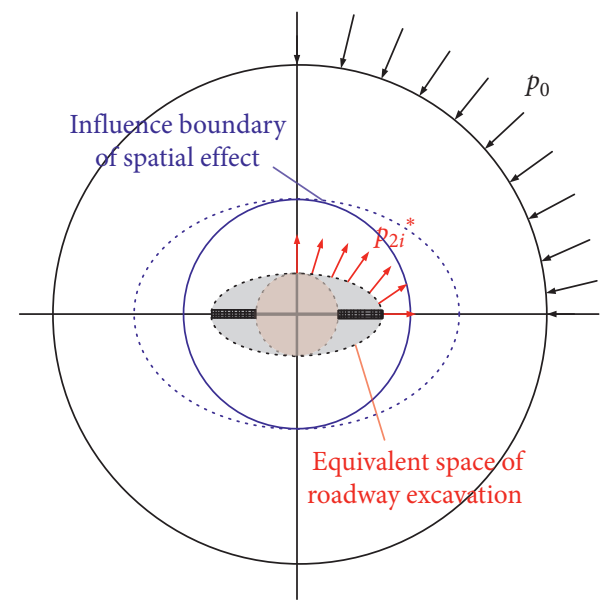

(d)

FIGURE 1: Stress model on bearing structure of surrounding rocks in an equivalent roadway excavation spatial effect: (a) the stress state of original rock; (b) after the roadway is dug; (c) after construction pressure-relief measures; (d) after construction reinforcement measures.

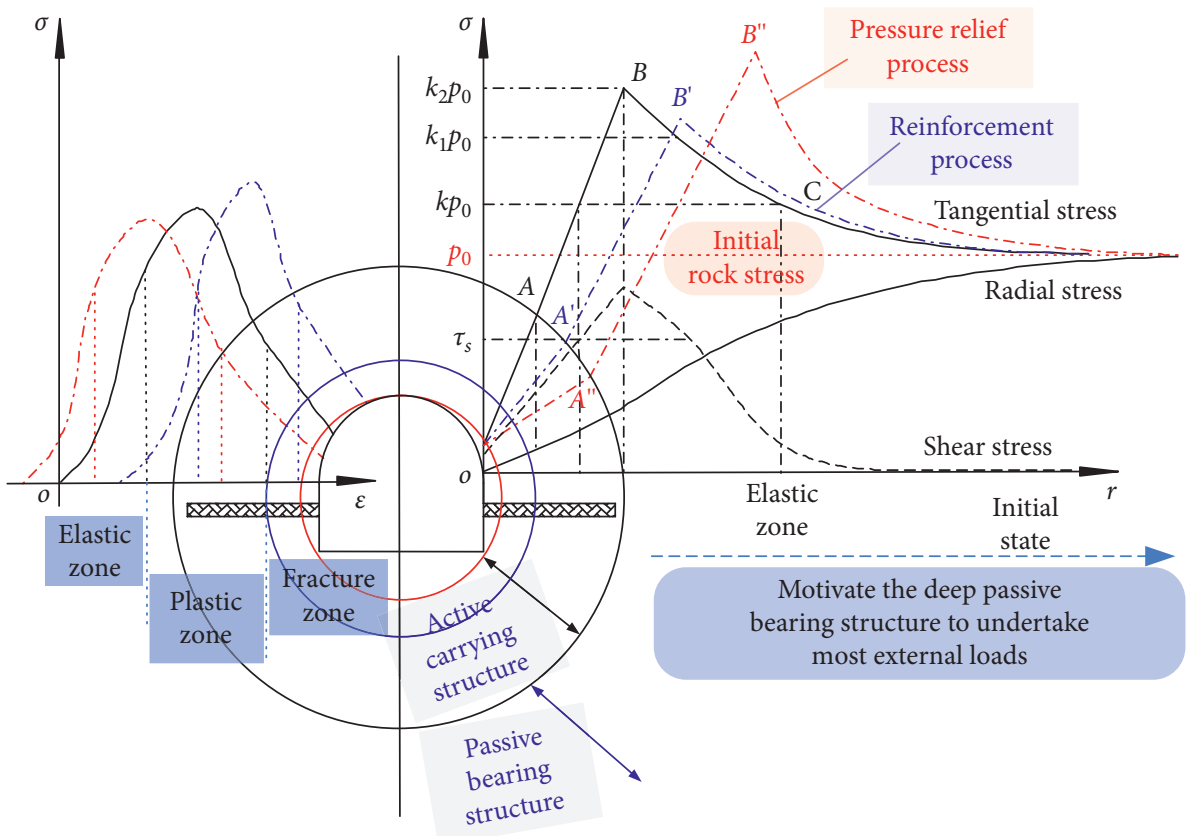

Figure 2: Distribution states of surrounding rock stress and strength features in a roadway. 


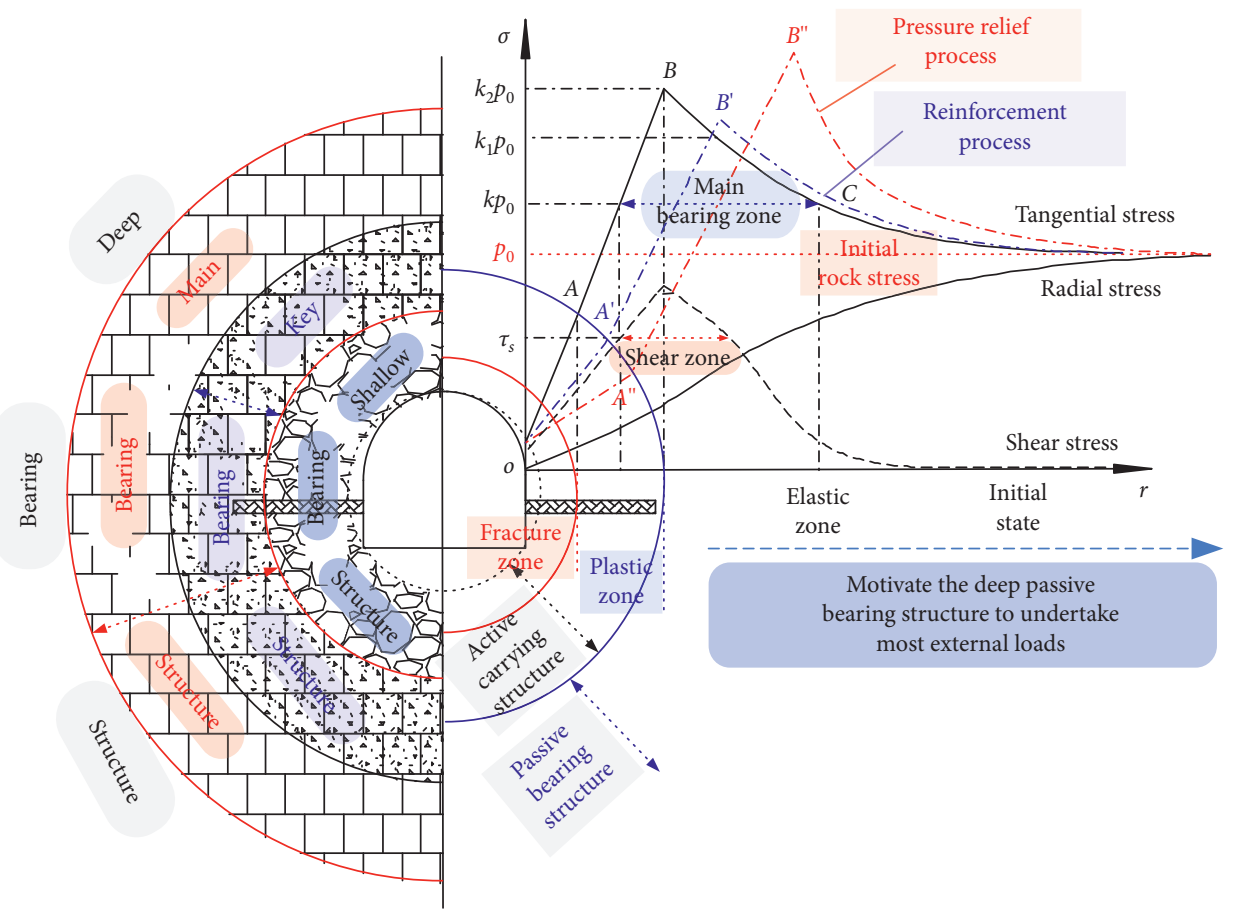

FIGURE 3: Relations between surrounding rock stress and bearing structure in a roadway.

and elastic zone near the peak line of surrounding rock stress in a roadway, which provides important references for stability of the whole bearing structure. Moreover, surrounding rocks in the tangential stress concentration zone $\left(k_{1} p_{0} \sim k_{2} p_{0}\right)$ are the key bearing circle. In addition, it can be known from evolutionary laws of surrounding rock fractures and stress field that the initiative bearing structure is formed by shallow surrounding rocks close to the progressive stress increasing zone on the excavation face and it is influenced by excavation unloading significantly. This initiative bearing structure undertakes surrounding rock stress and is failed firstly. The passive bearing structure is formed by deep surrounding rocks in the stress decreasing zone which is far away from the excavation surface, and these rock masses possess relatively strong bearing capacity. The unloading and reinforcement construction is applied initiatively to interfere surrounding rock stress distribution in a roadway and motivate the deep passive bearing structure to undertake most external loads, thus protecting shallow surrounding rocks under a low-stress state.

Hence, construction shall avoid secondary failure of the initiative bearing structure and motivate the bearing effect of the deep passive bearing structure fully in order to control surrounding rock stability in a high-stress roadway. According to the axis-changing theory and surrounding rock stress control technology in a roadway, the initiative unloading measures (large-diameter unloading pores and constructing pressure-relief grooves) are proposed to weaken harmful hulking deformation of surrounding rocks in the shallow broken zone. Moreover, the initiative bearing structural scope is expanded. Meanwhile, the deep passive bearing structure is motivated to support the safety of excavation space. Based on improvement of surrounding rock stress distribution, reinforcement measures (e.g., anchoring and grouting) are applied to form additional acting points on the initiative bearing structure, which is conducive to forming a completely closed bearing structure. Finally, a stable bearing structure which adapts to surrounding rock stress state is formed. In other words, the axial ratio $(g)$ of bearing structure in an equivalent roadway excavation spatial effect is equal to or approximately equal to the coefficient of horizontal pressure $(\lambda)$.

\section{Mechanical Characteristics and Bearing Structure of Roadway Surrounding Rock Mass}

3.1. Mechanical Model of Roadway Excavation. For the convenient theoretical analysis of influences of unloading and reinforcement construction on surrounding rock stress control, a mechanical model of roadway excavation was built (Figure 4). Some hypotheses are made: (1) surrounding rocks are homogeneous isotropic rock masses. (2) The roadway is long enough, and it can be simplified as a plane strain problem. (3) Surrounding rocks are in a stress field of homogeneous primary rocks, and influences of gravity gradients are ignored. (4) According to the full stress-strain curve of surrounding rocks in Figure 2, surrounding rocks after roadway excavation are divided into a fracture zone $\left(r_{b}\right)$ and a plastic softening zone $\left(r_{p}\right)$ as well as an elastic zone and primary rock stress zone.

The "temporal-spatial effect" in the process of roadway excavation is manifested by continuous deformation of influenced surrounding rocks as time goes on. Such deformation is analyzed along axial and radial directions (Figure 4). According to axial analysis, elasticoplastic 


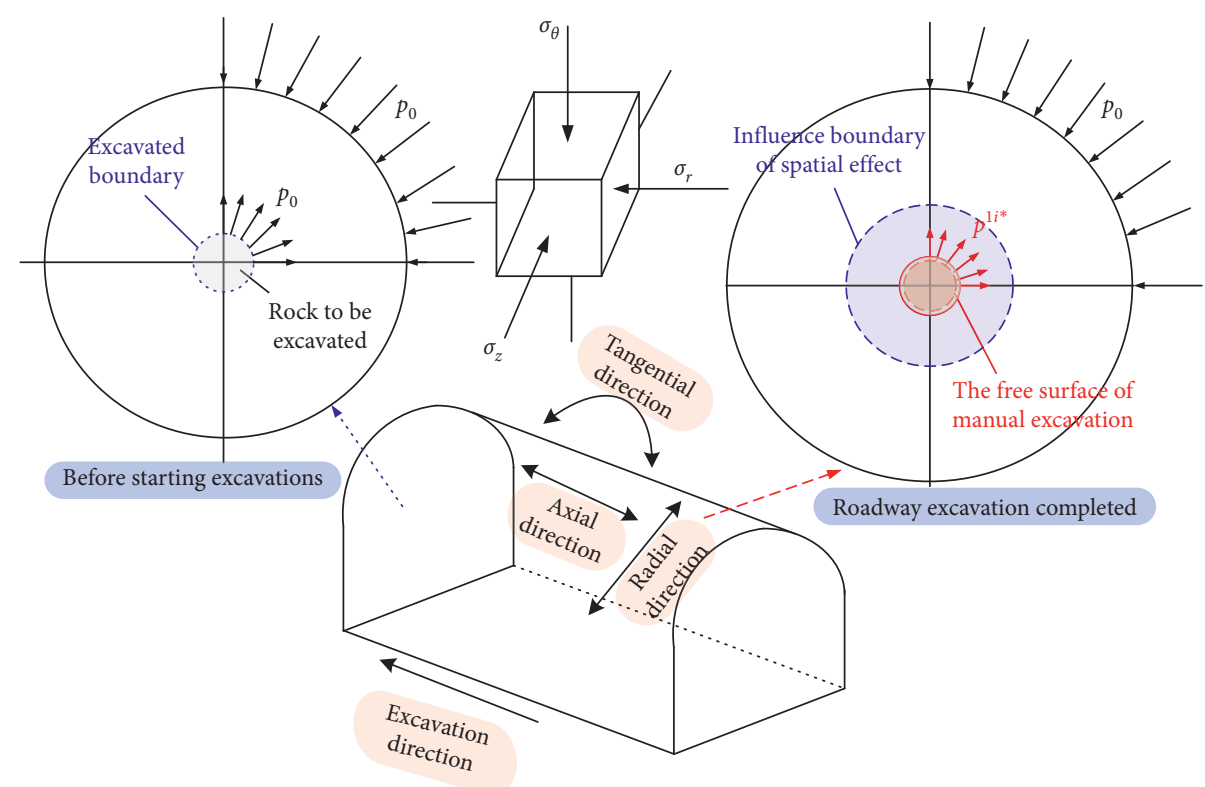

Figure 4: Mechanical model of roadway excavation.

deformation development and stress redistribution of surrounding rocks within a certain scope to the excavation face (generally $5 r_{0}$ to the excavation face) are restricted by the structural effect during excavation. It needs a time history to adjust stress distribution and bearing structures. Based on analysis of radial excavation face, the "excavating rock mass" and "surrounding rock" interact before roadway excavation, and they impose an interaction force on the excavation face (contact interface), which is known as the stress of primary rocks $\left(p_{0}\right)$. After the "excavating rock mass" is eliminated, a free face is formed. Unloading disturbances to surrounding rocks decline gradually from shallow to deep regions. This process causes inconsistent deformations from free face to deep regions or uncoordinated strain energy releasing. As a result, the free face is influenced by spatial effect within a certain scope.

3.1.1. Spatial Effect Adjustment and Evolutionary Analysis. Since unloading and reinforcement construction can influence spatial effect of the excavation face and secondary releasing effect of elastic-plastic deformation of surrounding rocks, unloading and reinforcement construction is transformed into an equivalent effect of stress field when establishing the mechanical model of roadway excavation. The mechanical models of spatial effect on roadway excavation face are shown in Figure 4. It can be seen from Figure 4 that, considering the surrounding rock excavation in a high-stress roadway, great surrounding rock deformation is developed. Without consideration of supporting forces, the acting forces $(p)$ at surrounding areas of the roadway have different meanings under different situations:

$$
p= \begin{cases}p_{0}, & \text { before starting excavations, } \\ p_{i}^{*}, & \text { roadway excavation completed, }\end{cases}
$$

Before roadway excavation, there is a stress of primary rocks $\left(p_{0}, \mathrm{MPa}\right)$ due to the interaction between "excavating rock masses" and "surrounding rocks." After roadway excavation and before supporting, the situation is simplified; that is, there is a virtual supporting force $\left(p_{i}^{*}, \mathrm{MPa}\right)$ with consideration of the equivalent spatial effects of the excavation face at surrounding areas of surrounding rocks. Supporting measure is applied: the supporting effect of the in situ excavating rock masses is used to support surrounding rocks through reaction forces of the passive supporting structure. Obviously, the supporting force can be ignored in relation to $p_{0}$. Therefore, elastic energies of surrounding rocks are not released completely, manifested by extruding convergence of surrounding rocks toward the free face. Construction measures which can protect more coordinated surrounding rock deformation from free face to deep regions or assure more consistent releasing of strain energies shall be used to control surrounding rock deformation.

Considering "spatial effect" of excavation, an elasticplastic mechanical analysis of influences of unloading and reinforcement construction on surrounding rock stress was carried out, and a more accurate theoretical calculation was given. Influenced by "spatial effect" of free face, releasing loads on the workblank tunnel section cannot reach the initial ground stress state immediately. Instead, it has a time history, and the variation process [24] of this releasing load with time is

$$
p_{0}(t)=p_{0}\left(1-0.7 e^{-\mathrm{mt}}\right)
$$

where $m$ is the coefficient of an exponential function $\left(m=3.15 v / 2 r_{0}\right)$.

$r_{0}$ is the radius of a roadway $(m), v$ is the average advancing speed of working face $(m / d)$, and $t$ is the initial time of sectional excavation. 
On this basis, the virtual radial supporting pressure of spatial effect on the roadway excavation face can be expressed as

$$
p_{i}^{*}(t)=p_{0}-p_{0}(t)=0.7 p_{0} e^{-m t} .
$$

In Figure 4 , there is a $p_{0}$ on surrounding rocks. Due to existence of spatial effect of excavation face, the equivalent mechanical effect is equal to the effect of stress $p_{i}^{*}$ within 5 times of roadway radius on the excavation surface. According to E. Hoek's fitting equation, the radial resilience displacement under a virtual supporting force $p_{i}^{*}$ is

$$
\begin{aligned}
u_{r_{0}}^{p_{i}^{*}} & =u_{r_{0}}(\infty)\left[1+\exp \left(-\frac{\left(x / r_{0}\right)}{1.10}\right)\right]^{-1.7}, \\
k(x) & =\left[1+\exp \left(-\frac{x}{r_{0} / 1.10}\right)\right]^{-1.7},
\end{aligned}
$$

where $x$ is the distance between the calculation face and the excavation face $(m)$. Suppose that $x$ is a constant in the range of $0<x<5 r_{0}$; it is a plane position on the studying excavation space. $u_{r_{0}}(\infty)$ is the radial displacement of surrounding rocks under the influence of $p_{0}$.

The spatial effect curve of the excavation face (E. Hoek curve) is shown in Figure 5. It can be seen from Figure 5 that, during unloading construction on the roadway excavation face, the stress releasing rate $k(x)$ increases, and thus the $p_{i}^{*}$ decreases. The radial displacement of roadway generally increases while the proportion of plastic displacement in the total elastic-plastic displacement increases, thus accelerating surrounding rock deformation toward convergence.

In addition, two important characterization factors of deformation in a roadway were analyzed, which are zero displacement point (radial displacement $=0$ ) and deepsurface ratio. The deep-surface ratio refers to the ratio between radial displacement at any deep point of surrounding rocks and radial displacement on surface:

$$
l_{r}=\frac{u_{r}}{u_{0}}
$$

where $u_{r}$ is the radial displacement of surrounding rock masses which are $r$ away from the roadway $(\mathrm{mm})$ and $u_{0}$ is the surrounding displacement of a roadway $(\mathrm{mm})$. Under stress conditions of primary rocks, the evolution law of deepsurface ratio is basically consistent with stress distribution caused by excavation. In other words, the deep-surface ratio attenuates from surrounding areas of the roadway to deep surrounding rocks according to the negative exponential curve $l_{r}=e^{-\alpha r}$ ( $\alpha$ is the coefficient related to lithology). The variation law of deep-surface ratio is shown in Figure 6. In the shallow fracture zone, surrounding rocks are damaged seriously, and they generally present extrusion deformation toward the free face, without restrictions. The deep-surface ratio is generally high. In the deep plastic zone, the external surrounding rocks are restricted by shallow surrounding rocks, and displacement deformation decreases gradually until reaching the zero displacement point. After unloading construction, deep-surface ratios in the shallow fracture

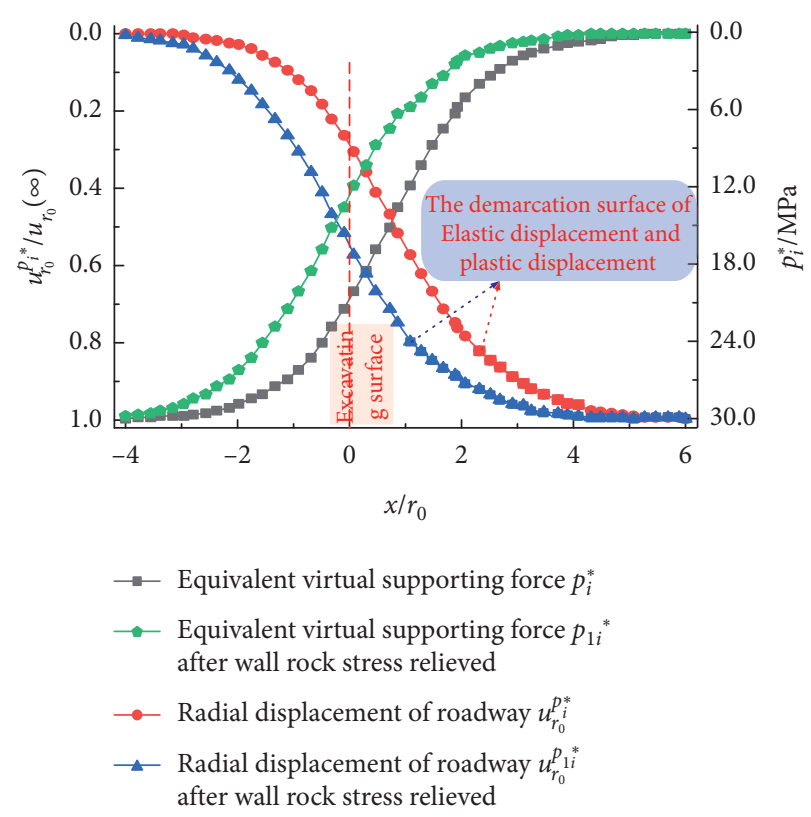

FIGURE 5: Virtual supporting force and corresponding radial displacement of roadway excavation face.

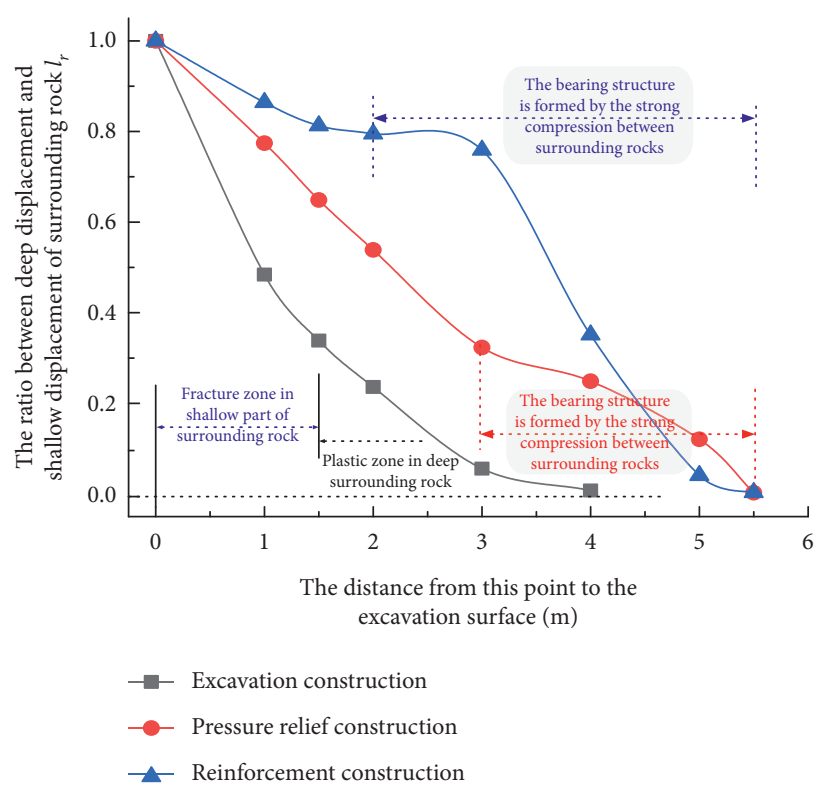

Figure 6: Deep-surface ratio of roadway surrounding rocks.

zone and deep plastic zone show consistent decreasing laws. As surrounding rock stress transfers to deep regions, the deep-surface ratio of deep surrounding rocks continues to change until reaching extrusion stability. Therefore, an extrusion bearing zone is developed in deep surrounding rocks. Reinforcement ensures coordinated deformation of shallow roadway surrounding rocks to share loads, and radial displacement of deep surrounding rocks declines significantly, thus forcing surrounding rocks to be stable. Therefore, the overall deformation from free face to deep surrounding rocks becomes more coordinated after unloading and reinforcement construction. In other words, 
radial strains at internal (shallow) and external (deep) sides of free face basically keep the same deviations, showing the same variation rate. As a result, elastic-plastic deformations of surrounding rocks in the unloading zone are released fully, which is beneficial for the formation of the secondary stress field and development of surrounding rock stability.

3.1.2. Dilatation Model of Surrounding Rocks. Postpeak mechanical properties of rocks are vital to study surrounding rocks stability in a roadway. Postpeak dilatation of rocks is an important cause of great surrounding rock deformation in a roadway; it is related to strain. The dilatation model is shown in Figure 7.

Surrounding rocks develop dilatation in the plastic softening zone and fracture zone. In the softening zone, the flow rule with consideration of volume expansion of rock masses is

$$
\varepsilon_{r}^{p}+\xi \varepsilon_{\theta}^{p}=0 .
$$

According to mechanical properties and full stress-strain curve $(\sigma-\varepsilon)$ of rocks in different zones, surrounding rocks in the fracture zone and plastic zone are behind the stress peak. Due to uncertainty of stress declining mode, mechanical properties show strong differences with the increase of deformation. The complexity lies in the nonlinear stressstrain relation. According to the Plasticity Theory, plastic strain is determined by the plastic potential, and plastic deformation of rocks generally observes the unassociated flow rule. In this case, it is believed that the plastic potential function $(I)$ has the same mathematical form with the yield function $(F)$ according to (11).

Surrounding rock stress shall meet the Mohr-Coulomb criteria at the occurrence of plastic yielding and fracture. The yield function can be expressed uniformly as

$$
\begin{aligned}
F & =\sigma_{\theta}-k_{\varphi} \sigma_{r}-\sigma_{c}=0, \\
k_{\varphi} & =\frac{1+\sin \varphi_{t}}{1-\sin \varphi_{t}}, \\
\sigma_{c} & =\frac{2 c_{t} \cos \varphi_{t}}{1-\sin \varphi_{t}}, \\
\varphi_{t} & =\arcsin \frac{2(1+w) \sin \varphi_{0}}{2+w\left(1+\sin \varphi_{0}\right)}, \\
c_{t} & =\frac{2(1+w) c_{0} \cos \varphi_{0}}{2+w\left(1+\sin \varphi_{0}\right)} \cdot \frac{1}{\cos \varphi_{t}},
\end{aligned}
$$

where $c_{0}$ is the cohesion ( $\mathrm{MPa}$ ) and $\varphi_{0}$ is an internal friction angle $\left({ }^{\circ}\right)$. In the engineering, the coefficient of intermediate principal stress $(w)$ is used to reflect the weighting coefficient of intermediate principal stress, and its values are in the range of $0 \leq w \leq 1$. The relations between the intermediate principal stress and the maximum principal stress $\left(\sigma_{1}\right)$ and minimum principal stress $\left(\sigma_{3}\right)$ can be expressed as

$$
w=\frac{\sigma_{2}-\sigma_{3}}{\sigma_{1}-\sigma_{3}} \text {. }
$$

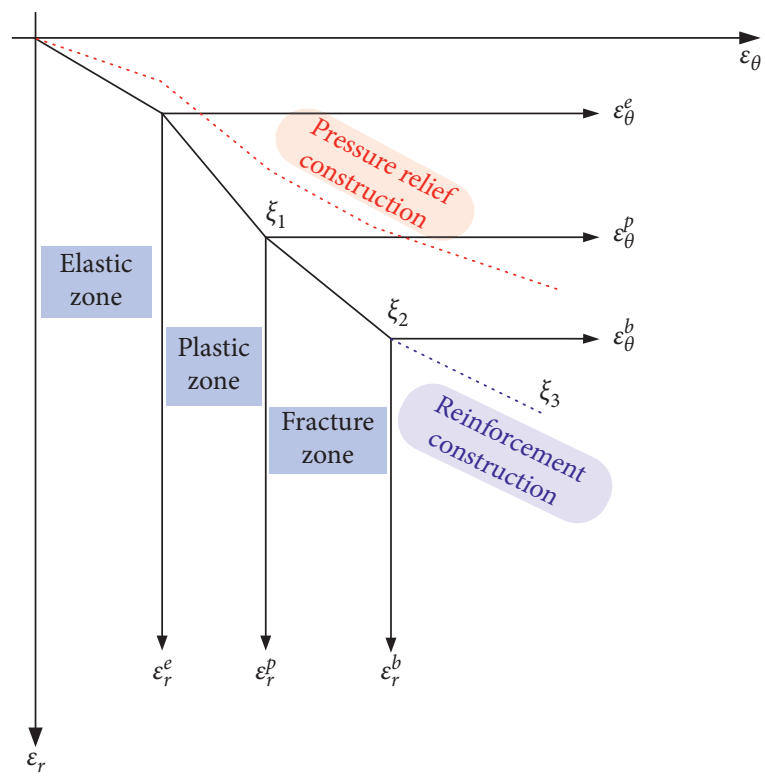

FIGURE 7: Strain model of roadway surrounding rocks.

The internal friction angle $(\varphi)$ in $F$ was replaced by the dilatation angle $(\psi)$, and then the expression of $I$ can be gained. Corresponding to the Mohr-Coulomb criterion, the plastic potential is

$$
I=\sigma_{\theta}-\xi \sigma_{r}
$$

According to the plastic potential theory,

$$
\mathrm{d} \varepsilon_{i j}^{p}=\mathrm{d} \Upsilon \frac{\partial I}{\partial \sigma_{i j}},
$$

where $I$ is the plastic potential function, $\varepsilon_{i j}^{p}$ is the plastic strain increment, $\sigma_{i j}$ is the stress tensor $(\mathrm{MPa})$, and $\mathrm{d} \Upsilon$ is the proportional coefficient related to plastic potential function: $\mathrm{d} \Upsilon \geq 0$.

According to (13) and (14),

$$
\left\{\begin{array}{l}
\mathrm{d} \varepsilon_{r}^{p}=\mathrm{d} \Upsilon \frac{\partial I}{\partial \sigma_{r}}=-\mathrm{d} \Upsilon \frac{1+\sin \psi_{\mathrm{t}}}{1-\sin \psi_{t}}, \\
\mathrm{~d} \varepsilon_{\theta}^{p}=\mathrm{d} \Upsilon \frac{\partial I}{\partial \sigma_{\theta}}=\mathrm{d} \Upsilon,
\end{array}\right.
$$

where $\Upsilon$ is the plastic strain.

Specifically, $\xi$ is defined as the dilatation parameter of surrounding rocks considering fracture zone and plastic zone, and $\xi>1$. It is the ratio of absolute radial plastic strain and absolute tangential plastic strain. Therefore, it can get

$$
\begin{aligned}
\xi & =k_{\psi_{t}}=\frac{1+\sin \psi_{t}}{1-\sin \psi_{t}}, \\
\psi_{t} & =\arcsin \frac{2(1+b) \sin \psi}{2+b(1+\sin \psi)},
\end{aligned}
$$

where surrounding rocks in the fracture zone and plastic zone develop dilatation and the dilatation angle is $\psi\left({ }^{\circ}\right)$. 
To analyze the harmful dilatation deformation of the fracture zone and plastic zone, the strength-stress ratio of surrounding rocks is introduced:

$$
S=\frac{\sigma_{c} \cdot s}{\sigma_{\theta}}
$$

where $\sigma_{c}$ is the uniaxial compressive strength of surrounding rocks $(\mathrm{MPa})$, and $s$ is the coefficient of rock integrity and it is within the range $0 \sim 1$. Unloading measures can provide a compensation space for dilatation deformation, decrease the strength-stress ratio, and adjust concentrated stress transferring to deep surrounding rocks (rock masses are in the three-directional stress state and have high strength to bear supporting pressure). Plastic potential refers to the surrounding rock stress needed for unit volume of surrounding rocks to develop plastic deformation. It can be seen from (13) and (14) that plastic potential function presents monotone increasing with changes of stress. This reflects the fact that unloading measures can decrease surrounding rock stresses and accelerate energy releasing from surrounding rocks in the fracture zone and plastic zone.

Dilatation of roadway surrounding rocks is influenced by confining pressure; such behaviors of surrounding rocks also present nonlinear change. The relation curves between dilatation rate and self-bearing capacity are shown in Figure 8. The dilatation rate is the ratio between swelling volume of surrounding rocks caused by extraction unloading and the original volume of surrounding rocks. It is related to development of surrounding rock fracture. The dilatation rate is $\nu=\Delta V / V$. The variation curve of dilatation rate is gained by analyzing displacement monitoring data of deep roadway surrounding rocks (Figure 8). Surrounding rocks in the shallow fracture zone are in the low-stress zone, thus resulting in significant dilatation to exceed the critical dilatation rate. Self-bearing capacity decreases significantly with the increase of dilatation rate in the shallow fracture zone. Therefore, unloading construction provides a compensation space for dilatation deformation of shallow surrounding rocks and decreases the harmful dilatation deformation. Reinforcement can increase bearing capacity of surrounding rocks, which is conducive to surrounding rock stability in a roadway.

\subsubsection{Surrounding Rock Softening and Residual Model.}

Under complicated and high-stress conditions, surrounding rocks suffer deteriorating mechanical properties (strength softening) when external loads reach the peak strength. In softening parameter expressions $k_{\varphi}$ and $\sigma_{c}$ during postpeak softening, cohesion $(c)$ and internal friction angle $(\varphi)$ might decrease to different extents until reaching the residual values with the increase of plastic strain of surrounding rocks. It is hypothesized that reduction of $c$ and $\varphi$ presents a linear relation with plastic strain. However, unloading and reinforcement measures can change the strength parameters of surrounding rocks. The mechanical model softening is shown in Figure 9.

In the plastic softening zone, both $c$ and $\varphi$ are negatively related to the plastic strain $\varepsilon_{\theta}^{p}$. In other words, $c$ and $\varphi$ are functions of $\varepsilon_{\theta}^{p}$. Then, it can be concluded that

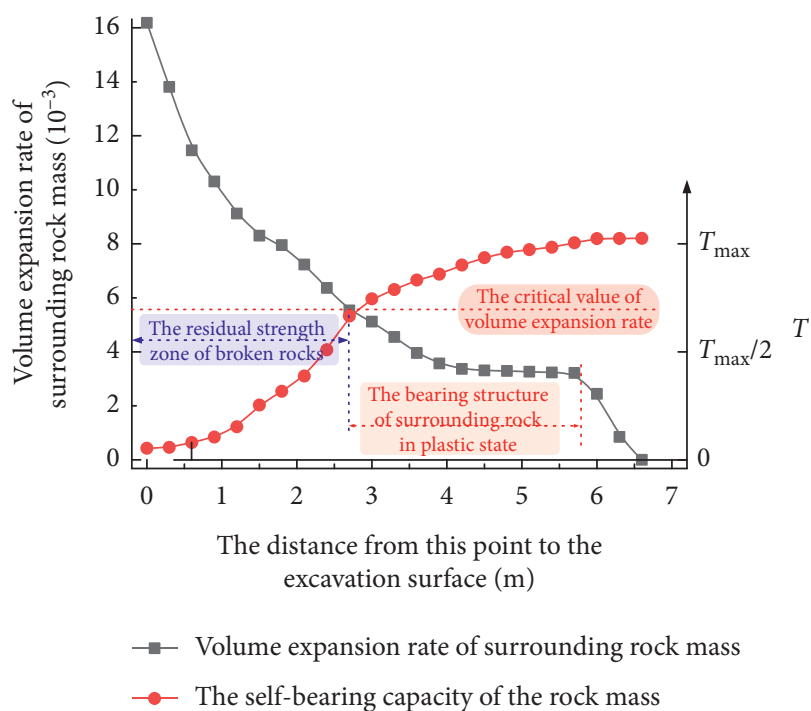

FIGURE 8: Relation curves between dilatation rate and self-bearing capacity of surrounding rocks.

$$
\left\{\begin{array}{l}
c_{p}=c_{0}-M_{c}\left(\varepsilon_{\theta}^{p}-\varepsilon_{\theta}^{e}\right), \\
\varphi_{p}=\varphi_{0}-M_{\varphi}\left(\varepsilon_{\theta}^{p}-\varepsilon_{\theta}^{e}\right),
\end{array}\right.
$$

where $c_{0}$ and $\varphi_{0}$ are initial values of surrounding rock strength parameters. $c_{p}$ and $\varphi_{p}$ are plastic softening values. $c_{b}$ and $\varphi_{b}$ are residual values. $\varepsilon_{\theta}^{e}$ is the strain corresponding to the peak strength. The softening modulus of cohesion $\left(M_{c}\right)$ and the softening modulus of internal fraction angle $\left(M_{\varphi}\right)$ are determined according to the ratios of effective plastic strain increment $\left(\Delta \varepsilon_{\theta}^{p}\right)$ with $\Delta c$ and $\Delta \varphi$.

Therefore, the strength condition that surrounding rocks in the plastic softening zone meet is

$$
\begin{aligned}
F^{p} & =\sigma_{\theta}^{p}-\frac{1+\sin \varphi_{t}^{p}}{1-\sin \varphi_{t}^{p}} \sigma_{r}-\frac{2 c_{t}^{p} \cos \varphi_{t}^{p}}{1-\sin \varphi_{t}^{p}}=0, \\
\sin \varphi_{t}^{p} & =\frac{2(1+b) \sin \varphi_{p}}{2+b\left(1+\sin \varphi_{p}\right)}, \\
c_{t}^{p} & =\frac{2(1+b) c_{p} \cos \varphi_{p}}{2+b\left(1+\sin \varphi_{p}\right)} \cdot \frac{1}{\cos \varphi_{t}^{p}} .
\end{aligned}
$$

In the fracture residual zone, $c$ and $\varphi$ of surrounding rocks are softened to residual strength values $c_{b}$ and $\varphi_{b}$, respectively. Therefore, the strength condition that surrounding rocks in the fracture residual zone meet is

$$
F^{b}=\sigma_{\theta}^{b}-\frac{1+\sin \varphi_{t}^{b}}{1-\sin \varphi_{t}^{b}} \sigma_{r}-\frac{2 c_{t}^{b} \cos \varphi_{t}^{b}}{1-\sin \varphi_{t}^{b}}=0 .
$$

According to the theory of plasticity, fracture degree becomes different with the development of plastic deformation of surrounding rocks. Therefore, yield strengths of rocks are different under the peak state and residual state. To characterize evolutionary characteristics of mechanical properties of surrounding rocks with plasticity, a plastic 


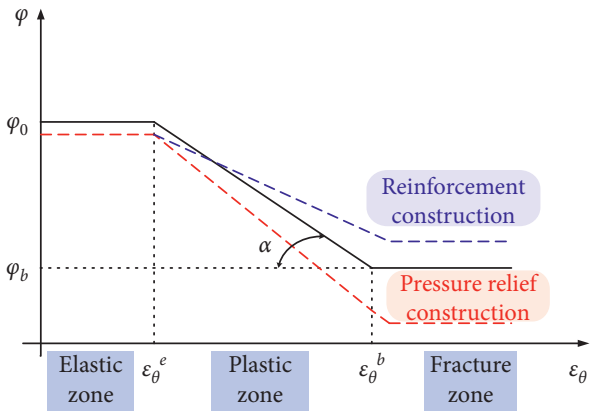

(a)

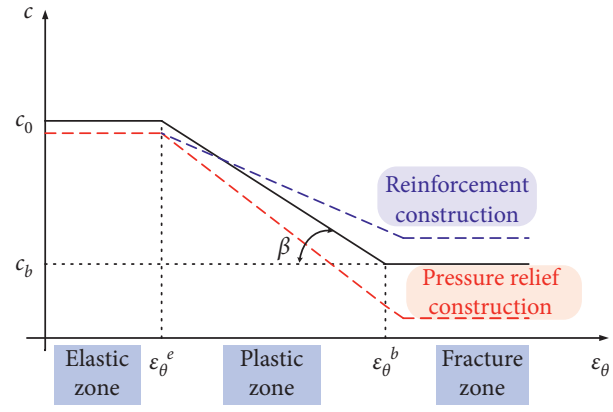

(b)

FIGURE 9: Surrounding rock softening model in a roadway: (a) the softening models for internal friction angle $\varphi$ of surrounding rock mass; (b) the softening models for cohesion $c$ of surrounding rock mass.

internal variable that reflects the plastic evolution degree was introduced. To simplify the research problem, it is hypothesized that surrounding rocks develop shear failure. Hence, the equivalent plastic shearing strain was chosen to define the internal variable $\kappa$. The plastic internal variable with consideration of influences of surrounding rocks is

$$
\left\{\begin{array}{l}
\kappa=\int \mathrm{d} \kappa, \\
\mathrm{d} \kappa=\frac{\mathrm{d} \bar{e}^{p}}{f\left(\sigma_{3} / p\right)},
\end{array}\right.
$$

where $\mathrm{d} \bar{e}^{p}=\sqrt{(2 / 3) \mathrm{d} e^{p}: \mathrm{d} e^{p}}$ is the tensor of equivalent plastic shear strain increment. $f\left(\sigma_{3} / p\right)$ is a function of surrounding rock $\sigma_{3}$. A compressive stress $(p)$ is introduced for dimensionless processing (unit stress value) of confining pressure. The form of function can be gained through fitting of cyclic loading-unloading test data. To reflect the influencing law of confining pressure more accurately, a 3-parameter power function-type confining pressure function was chosen:

$$
f\left(\frac{\sigma_{3}}{p}\right)=A_{1}+A_{2}\left(\frac{\sigma_{3}}{p}\right)^{B}
$$

where $A_{1}, A_{2}$, and $B$ are parameters for fitting.

It can be seen form (21) and (22) that $\kappa$ is viewed as 0 at initial yielding and its value is 1 at the residual strength point. The postpeak strain softening index $(\Gamma)$ was introduced to analyze the evolutionary process of postpeak mechanical properties of surrounding rocks. The $\Gamma$ can be expressed as

$$
\Gamma=1+\left(\frac{M_{r}}{M_{p}}-1\right)(\kappa)^{l}=1+(\chi-1)(\kappa)^{l},
$$

where $M_{\mathrm{p}}$ is the mechanical parameter corresponding to the peak strength, $M_{\mathrm{r}}$ is the mechanical parameter corresponding to the residual strength, and $\chi$ is the variation amplitude of mechanical parameters of rocks from peak strength to residual strength. An exponential function $(l)$ is introduced to describe the nonlinear relationship between the postpeak mechanical properties and plastic deformation. Since $l$ is related to fracture degree of surrounding rocks, differences of mechanical properties among internal units are more prominent if the fracture degree is higher, thus increasing the nonlinear correlation accordingly. For the convenience of study, a damage variable is introduced to define the expression of $l$ :

$$
l=D_{s}=1-\frac{\widetilde{S}}{S},
$$

where $D_{s}$ is the damage variable, $S$ is the cross sectional area of rock materials under zero damage, and $S(\sim)$ is the effective bearing area after rock damage. For the integral rocks, $S(\sim)=S$ and $D_{s}=0$. Under this circumstance, $l$ is 0 for integral rocks. For completely fractured rocks, $S(\sim)=0$, $D_{s}=1$, and $l=1$. The relation curve between $\Gamma$ and $\kappa$ is shown in Figure 10.

It can be seen from Figure 10 that surrounding rocks reach the initial yield condition by stresses caused by advancing excavation and then develop plastic deformation. Subsequently, strength of surrounding rocks decreases from the peak to residual strength gradually ( $\kappa$ increases gradually from 0 to 1 ), and the cohesion decreases to the residual value when $\kappa=1$. In this process, cohesion of surrounding rocks decreases quickly, while internal friction angle increases slowly in the postpeak stage. Under this circumstance, surrounding rocks mainly experience crack cut-through. With the continuous development of internal damage cracks in surrounding rocks, the plastic internal variable, attenuation amplitude $(\chi)$, and fracture degree $(l)$ are increased, thus resulting in inconsistent strains among units of surrounding rocks divided by internal cracks. As a result, the strain coordination is poor, so that surrounding rock strength parameters are easy to change suddenly (brittle falling stage). Cohesion strength decreases and frictional strength increases, accompanied by sliding of slightly inclined cracks and generation of a slip surface. Hence, unloading measures can improve distribution state of surrounding rock stresses, while reinforcement measures can 


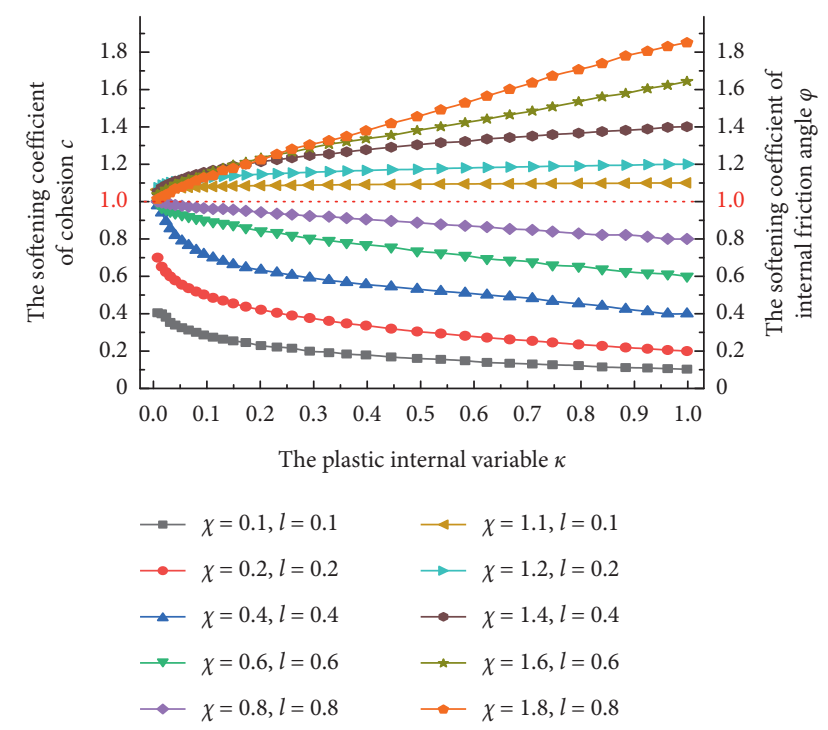

FIGURE 10: Evolutionary curve of $\Gamma$ of roadway surrounding rocks.

further increase residual strength of broken surrounding rocks.

\subsection{Bearing Structure of Roadway Surrounding Rocks}

3.2.1. Constitutive Model of Surrounding Rock Failure. Mechanical properties and strength of roadway surrounding rocks are determined by fracture development under surrounding rock stresses, thus determining the bearing structural strength of surrounding rocks. Based on the above postpeak strength model and dilatation characteristics, influences of unloading and reinforcement measures on bearing structure of surrounding rocks are analyzed by combining the full stress-strain curves of rocks. It can be seen from Figure 11 that the stress path and mechanical characteristics of rock unit model in a roadway are simplified as follows. Influenced by redistribution of surrounding rock stresses caused by excavation unloading, it is a viscoelasticity stage before the initial loading peak of surrounding rocks, approximately conforming to linear elastic Hooke's law. Shallow surrounding rocks enter the postpeak stage under influences of stress adjustment. Unloading measures accelerate surrounding rocks to enter the brittle falling stage I. Strain increment of rock unit is small, but the strength of surrounding rocks declines significantly, accompanied by development of rock fractures to release high stress. Therefore, shallow surrounding rocks are in the low-stress zone. Due to unloading measures, surrounding rocks have to be adjusted and enter the softening stage II to adapt to redistribution of surrounding rock stresses. In this stage, cracks in shallow surrounding rocks close and slip, causing great surrounding rock deformations and gradual reduction of strengths due to friction effect. As a result, fractures in surrounding rocks are closed because of stress in the brittle falling stage, thus realizing adjustment of initiative bearing structure of shallow surrounding rocks. Finally, surrounding rocks enter the residual strength stage III. With the continuous convergence and deformation of fractured

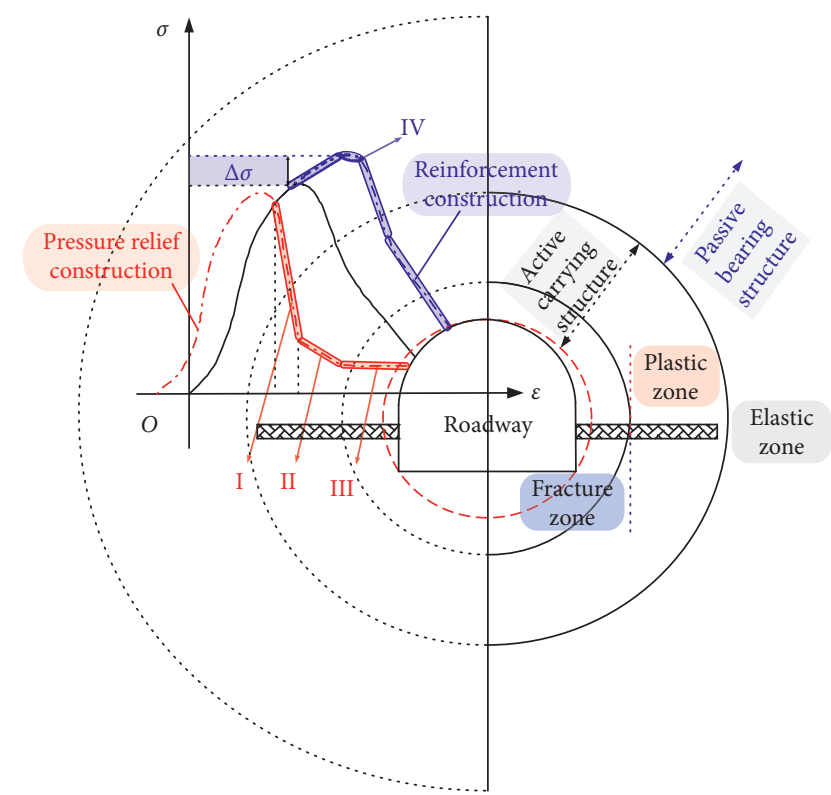

FIGURE 11: Mechanical characteristic model of surrounding rocks.

surrounding rocks, surrounding rock strength tends to be stable residual strength. Reinforcement measures are mainly applied to postpeak broken surrounding rocks. Adopting reinforcement measures in the postpeak reinforcement stage IV can increase residual strength, improve integral stability, and strengthen the self-bearing capacity. On this basis, surrounding rocks in the elastic zone mainly develop axial strain and have strong bearing capacities. Surrounding rocks in the plastic zone begin to be cracked, and later deformation is intensified significantly, mainly manifested by dilatation deformation. Surrounding rocks in the shallow fracture zone are broken completely and only have residual strength, accompanied by synchronous growths of lateral strains and axial strains.

\subsubsection{Adjustment and Evolutionary History of Bearing} Structure of Surrounding Rocks. The adjustment and evolutionary history of bearing structure are analyzed based on the above mechanical properties from the perspectives of stress distribution state and macroscopic bearing structure of surrounding rocks.

Surrounding rock stress state in different zones is changed due to radial unloading along the excavation face. Hence, surrounding rocks fail in order to adapt to the new stress state, and the bearing structure is adjusted by the interaction among rock blocks formed during surrounding rock failure. After unloading, shallow broken surrounding rock blocks are restricted by failure structure, and there is an interaction force $F^{*}$. Moreover, $F^{*}$ changes with the variation of surrounding rock failure modes (Figure 12(a)). Vertical bearing stress on shallow surrounding rocks decreases significantly after unloading measures. As a result, surrounding rock strength decreases, causing brittle falling. The radial surrounding rocks begin to transfer and converge circumferentially from the excavation face to deep regions and are then extruded and adjusted, entering the softening 


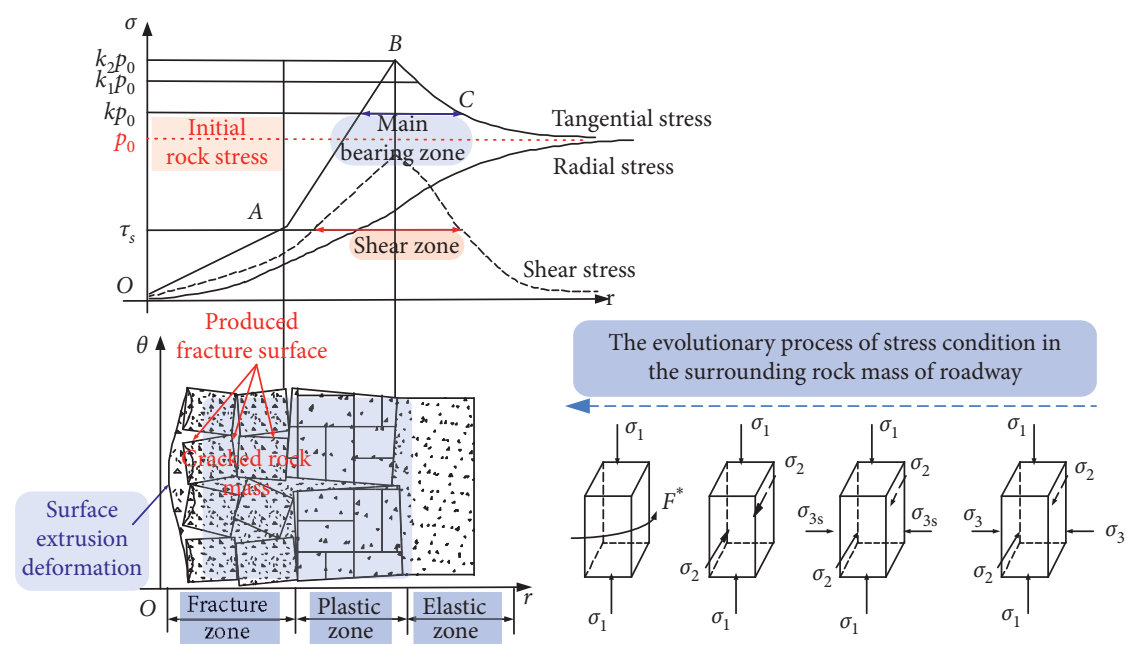

(a)

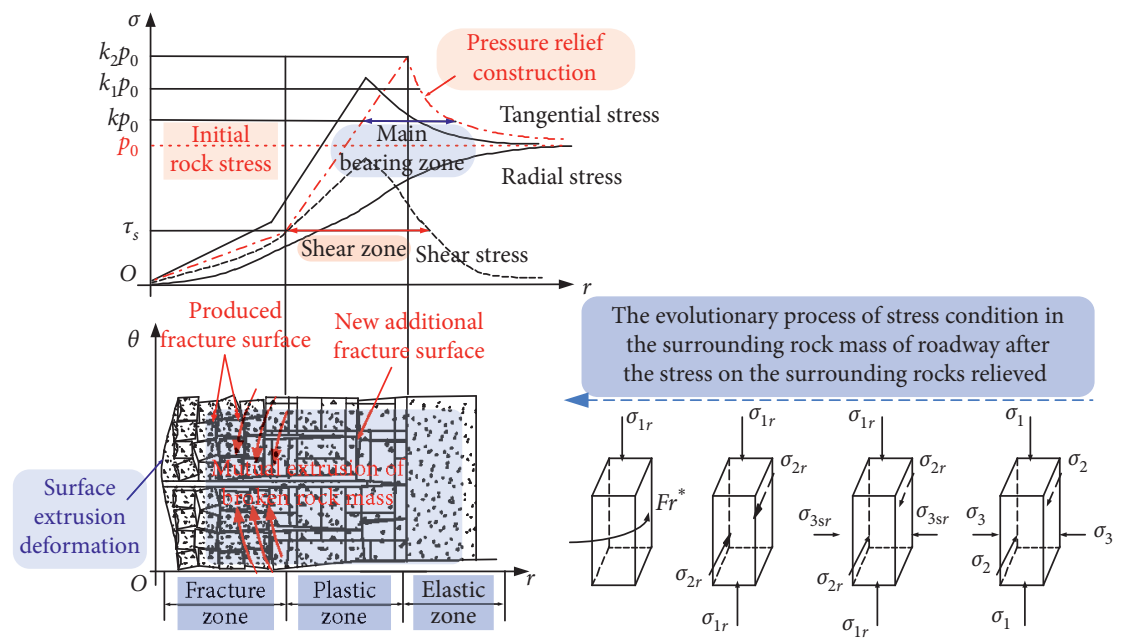

(b)

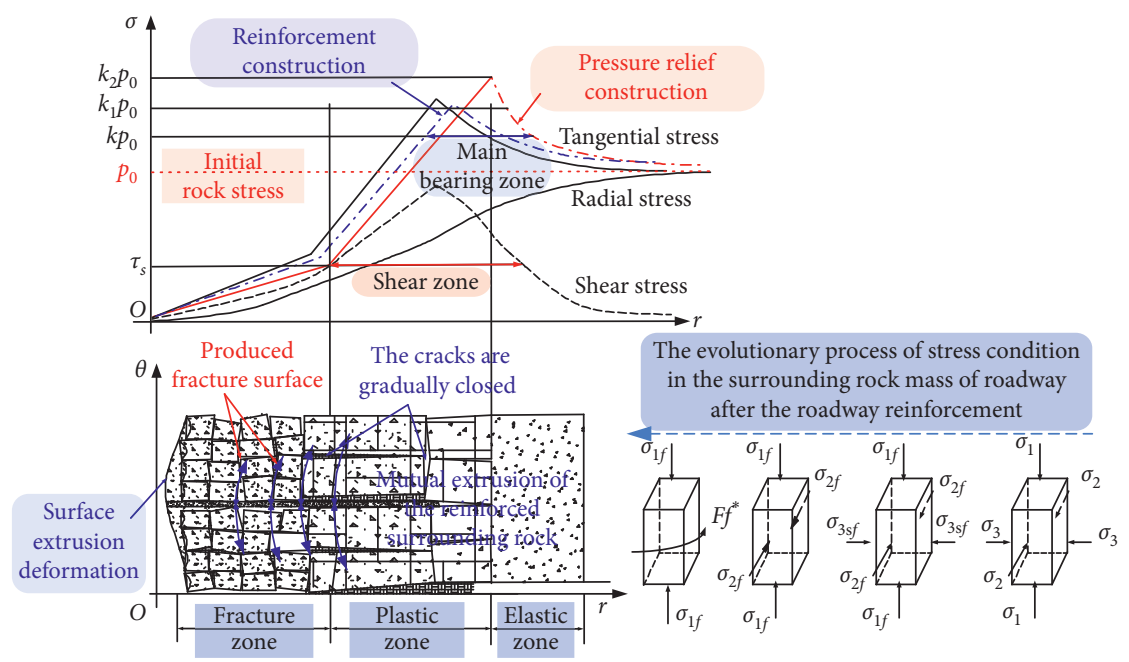

(c)

FIGURE 12: Evolutionary history of bearing structure of surrounding rocks and stress distribution states: (a) variation process of surrounding rock stress state after roadway excavation; (b) variation process of surrounding rock stress state after unloading; (c) variation process of surrounding rock stress state after reinforcement. 
stage. Unloading measures weaken malignant expansion of the loose circle caused by harmful deformation of shallow surrounding rocks. Moreover, surrounding rock stresses are adjusted again for secondary bearing of surrounding rocks in the initiative bearing zone, cracks in compressed surrounding rocks expand to deep regions along the radial direction, and secondary cracks are produced. The passive bearing structure of deep is motivated to undertake the high stress and protect the shallow broken surrounding rocks (Figure 12(b)). Reinforcement is applied to the shallow postpeak broken surrounding rocks to increase their residual strength, strengthen mutual meshing force among shallow broken rock blocks, and provide circumferential stress compensation to surrounding rocks, thus forming a closed free face radially, improving the acting state of bearing structure (Figure 12(c)).

\section{Numerical Simulation}

4.1. Numerical Simulation Schemes and Modeling. The largediameter pressure-relief drilling is easily used in the field construction of high-stress roadway. Therefore, largediameter pore based unloading of roadway surrounding rocks and surrounding rock stress field distribution characteristics after reinforcement as well as their influences on surrounding rock stability were simulated by FLAC ${ }^{3 \mathrm{D}}$ software; it is used to verify the above theory. A geometric model was constructed according to the simulation scheme (Figure 13). The roadway with a size of $3.4 \mathrm{~m} \times 2.6 \mathrm{~m}$ was in sandy mudstone. Diameter and depth of pores for unloading on two roadway sides were $0.3 \mathrm{~m}$ and $3.0 \mathrm{~m}$, respectively. The external dimension of the model was $105 \mathrm{~m}$ (length) $\times 25 \mathrm{~m}$ (width) $\times 124.93 \mathrm{~m}$ (height). The model meshing density was increased near the roadway surrounding rocks. The model had a constraint of horizontal movement along the $Y$ direction and a constraint of vertical movement at bottom boundary. On the upper boundary of the model, a uniformly distributed load (16.625 MPa) was applied according to about $700 \mathrm{~m}$ thickness of the overlying strata, and the coefficient of horizontal pressure was determined to be 1.2. The mechanical parameters of rock strata were gained from numerical simulation by combining field surrounding rock characteristics (Table 1). The constitutive model is an elasticplastic model, and the Mohr-Coulomb criterion is chosen as the yielding criterion. The maximum shearing stress is the key factor of surrounding rock failure. The maximum shearing stress is

$$
\tau_{\max }=\frac{1}{2}\left(\sigma_{1}-\sigma_{3}\right)
$$

\subsection{Analysis of Simulation Results}

4.2.1. Distribution Characteristics of Surrounding Rock Stress. Distribution of surrounding rock stress is shown in Figure 14. According to the analysis, unloading and reinforcement measures are applied to intervene the distribution state and transmission path of surrounding rock stress within the limited scope to the free face, forming a closed surrounding rock stress path and accelerating adjustment of surrounding rock stability. After roadway excavation, surrounding rock stress transfers to the free face, manifested by convergence and extrusion of surrounding rocks on the roadway section. After unloading measures, the transmission direction of surrounding rock stresses is changed and they begin to concentrate in unloading regions. After reinforcement measures, surrounding rock stresses concentrate in the reinforcing zones. Surrounding rocks in the reinforcing zones can provide supporting zones for bearing structures. It can be seen from Figure 15 that with adjustment of surrounding rock stress distribution state, surrounding rocks in the reinforcing zones on both sides of roadway develop reversed stresses, and reinforcement measures are applied to resist convergence deformation of surrounding rocks, thus enabling the increase of bearing capacity of shallow surrounding rocks. This conforms to the above theoretical analysis results of surrounding rock stress and bearing structural adjustment.

4.2.2. Bearing Structural Stability of Roadway Surrounding Rocks. The maximum principal stress differences of roadway surrounding rocks are listed in Table 2. Distribution of peak positions is shown in Figure 16. Based on the analysis, unloading and reinforcement measures on roadway sides can change the peak positions of principal stress differences, thus adjusting the form of bearing structural. After unloading measures, the maximum principal stress difference of roadway surrounding rocks is decreased by about 12.57 $\mathrm{MPa}$, and the peak moves toward the deep region by $2.5 \mathrm{~m}$. The maximum principal stress difference on the roof is decreased by about $0.59 \mathrm{MPa}$, and the peak moves toward the free face by $1.0 \mathrm{~m}$. The maximum principal stress difference on the floor is decreased by about $0.74 \mathrm{MPa}$, and the peak moves toward deep regions by $0.5 \mathrm{~m}$. After reinforcement measures, the maximum principal stress differences on roadway sides and floor are increased by $2.24 \mathrm{MPa}$ and $0.66 \mathrm{MPa}$, and peaks both move toward the free face by $0.5 \mathrm{~m}$. However, the maximum principal stress difference on the roof still decreases by $0.1 \mathrm{MPa}$, and the peak position remains unchanged. Therefore, surrounding rock stresses and bearing structure are adjusted gradually to promote reinforcing zones on both sides of roadway as the supporting zones of the bearing structure.

In addition, connecting lines of maximum principal stress differences are shown in Figure 16. Obviously, the ratio between the distance from peaks at two sides to the roadway $(3.0 \mathrm{~m})$ and the distance from roof and floor peaks to excavation space $(2.5 \mathrm{~m})$ is 1.2 , which is equal to the coefficient of horizontal pressure applied to the model. In other words, surrounding rocks collapse. Finally, the long axis direction of the excavation space is consistent with the direction of maximum principal stress of primary rocks. Unloading measures are equal to increasing the span of free face and optimizing the axial ratio of roadway excavation. Reinforcement measures promote surrounding rocks to form a " $\Omega$-shaped" bearing structure (Figures 14 and 15). Stresses on the roof transfer to deep regions on both sides of 


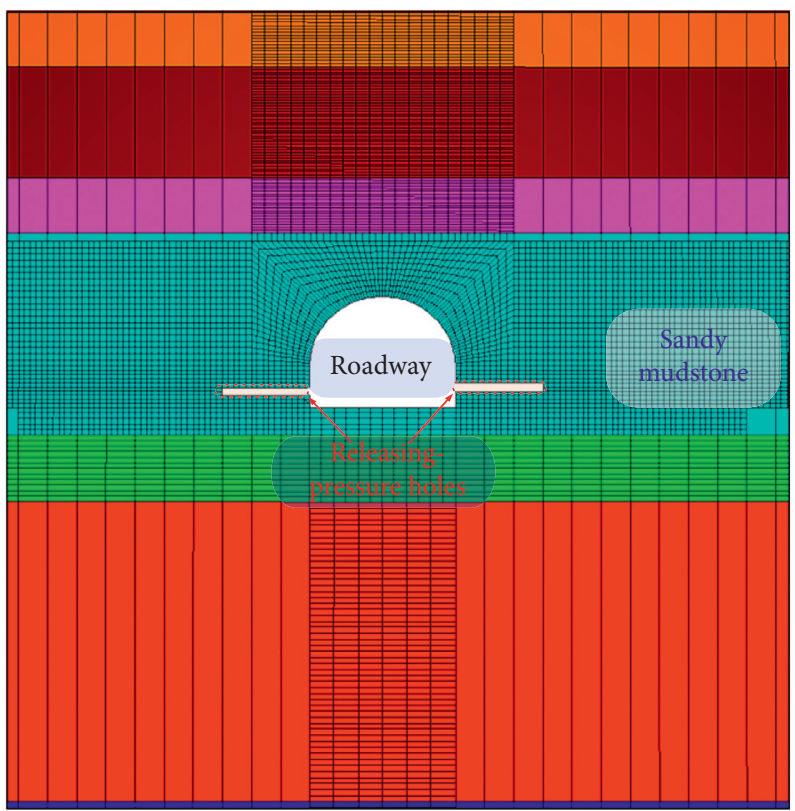

Figure 13: Numerical simulation model.

TABle 1: Numerical simulation on mechanical parameters of rocks.

\begin{tabular}{|c|c|c|c|c|c|}
\hline Names & $\begin{array}{l}\text { Bulk modulus of elasticity } \\
(\mathrm{e} 9 \mathrm{~Pa})\end{array}$ & $\begin{array}{l}\text { Maximum modulus of shear } \\
\text { modulus }(\mathrm{e} 9 \mathrm{~Pa})\end{array}$ & $\begin{array}{c}\text { Cohesion } \\
(\mathrm{e} 6 \mathrm{~Pa})\end{array}$ & $\begin{array}{c}\text { Internal friction } \\
\text { angle }\left({ }^{\circ}\right)\end{array}$ & $\begin{array}{c}\text { Tensile strength } \\
(\mathrm{e} 6 \mathrm{~Pa})\end{array}$ \\
\hline Fine sandstone & 5.03 & 2.40 & 4.280 & 42 & 2.020 \\
\hline Mudstone & 2.49 & 0.83 & 2.020 & 30 & 0.640 \\
\hline Siltstone & 5.72 & 2.29 & 3.270 & 38 & 2.180 \\
\hline Coal & 1.81 & 0.55 & 1.440 & 32 & 0.530 \\
\hline $\begin{array}{l}\text { Sandy } \\
\text { mudstone }\end{array}$ & 4.97 & 2.53 & 2.120 & 32 & 0.708 \\
\hline $\begin{array}{l}\text { Piebald } \\
\text { mudstone }\end{array}$ & 5.02 & 2.35 & 2.150 & 31 & 0.845 \\
\hline
\end{tabular}
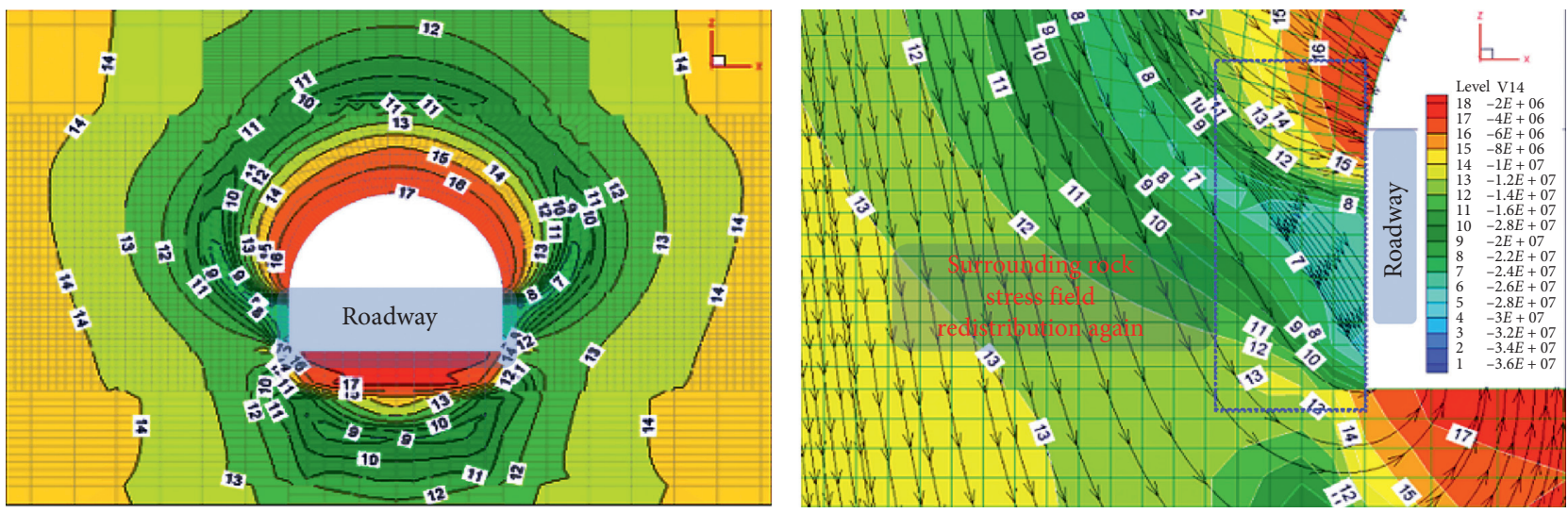

(a)

Figure 14: Continued. 

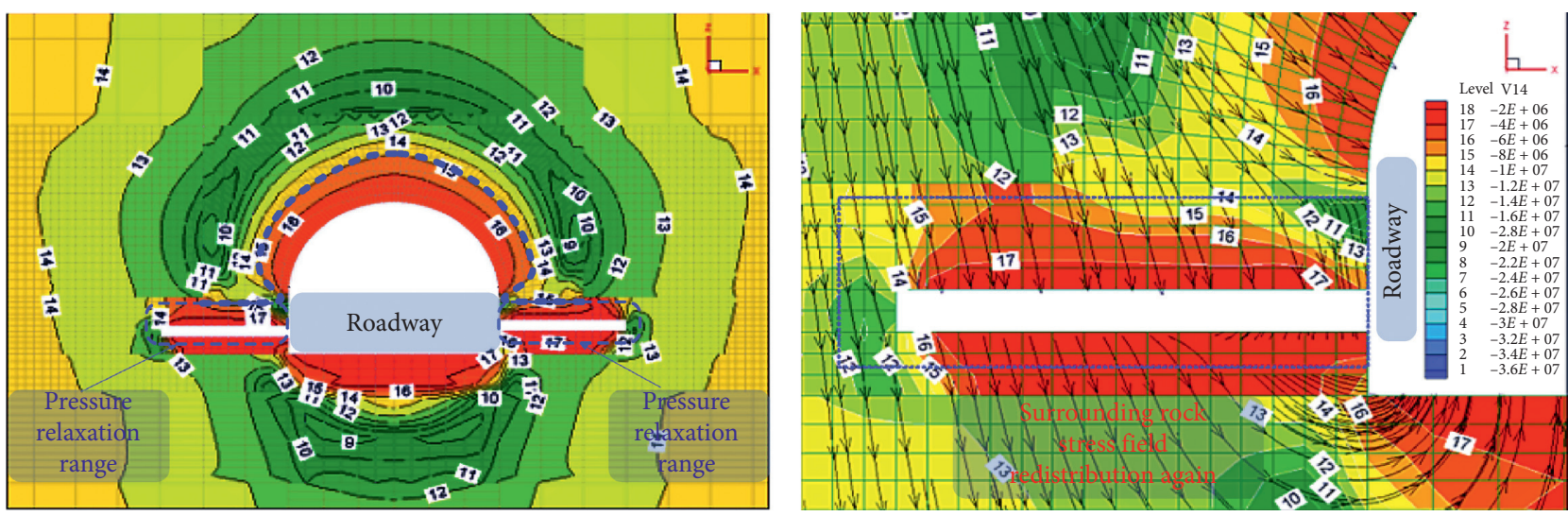

(b)
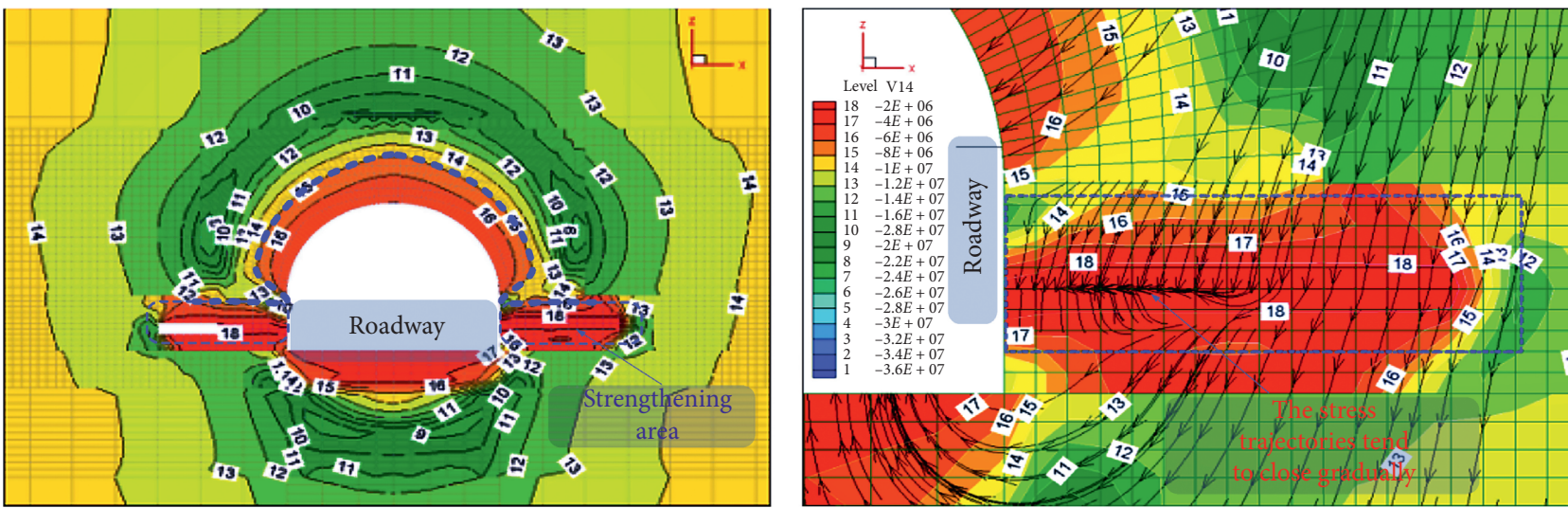

(c)

FIGURE 14: Distribution and path vector graphs of surrounding rock stresses: (a) distribution state of surrounding rock stress after excavation; (b) distribution state of surrounding rock stress unloading measures; (c) distribution state of surrounding rock stress after reinforcement measures.

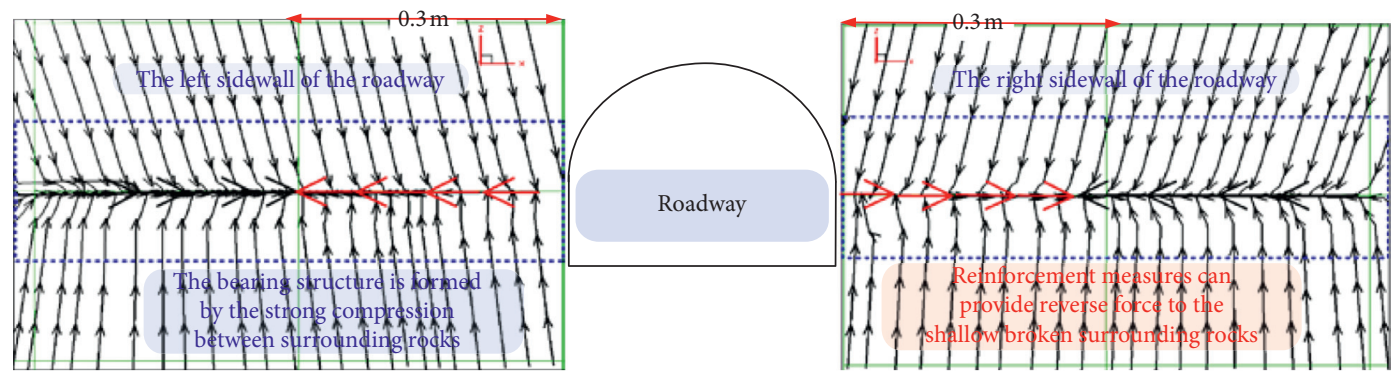

Figure 15: Partial enlarged view of surrounding rock stress path vector.

TABLE 2: Maximum principal stress difference of roadway surrounding rocks.

\begin{tabular}{lcccccc}
\hline Construction state & $\begin{array}{c}\text { The maximum principal stress difference and its distribution states } \\
\text { Roof }\end{array}$ & $\begin{array}{l}\text { Distance to the roof } \\
(\mathrm{MPa})\end{array}$ & $\begin{array}{c}\text { Distance to the sidewall } \\
(\mathrm{m})\end{array}$ & $\begin{array}{c}\text { Floor } \\
(\mathrm{MPa})\end{array}$ & $\begin{array}{c}\text { Distance to the floor } \\
(\mathrm{m})\end{array}$ & $\begin{array}{c}\mathrm{MPa}) \\
(\mathrm{m})\end{array}$ \\
\hline $\begin{array}{l}\text { Excavation construction } \\
\begin{array}{l}\text { Pressure-relief } \\
\text { construction }\end{array}\end{array}$ & 24.0171 & 1.0 & 19.4470 & 3.5 & 19.9614 & 2.5 \\
$\begin{array}{l}\text { Reinforcement } \\
\text { construction }\end{array}$ & 11.4483 & 3.5 & 18.8559 & 2.5 & 19.2168 & 3.0 \\
\hline
\end{tabular}




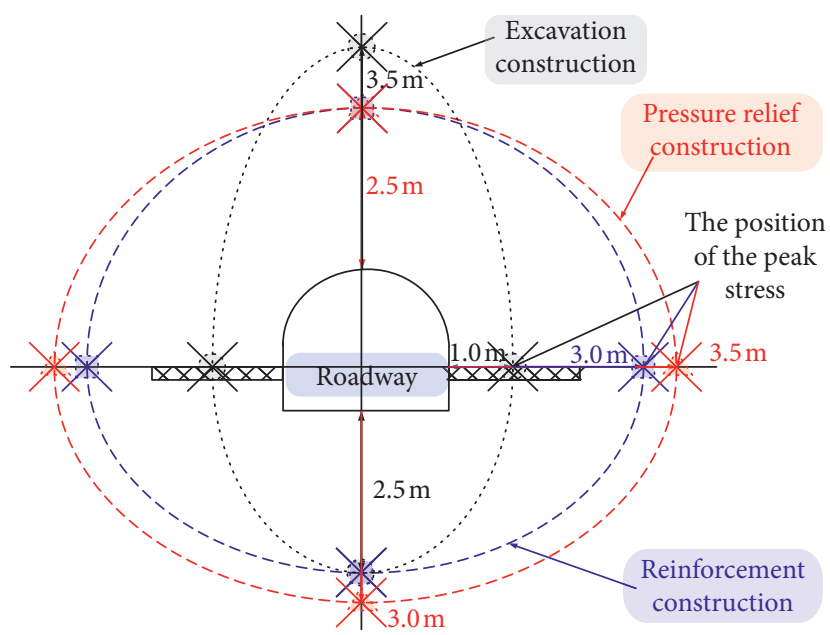

FiguRE 16: Distribution of principal stress difference peaks of roadway surrounding rocks.

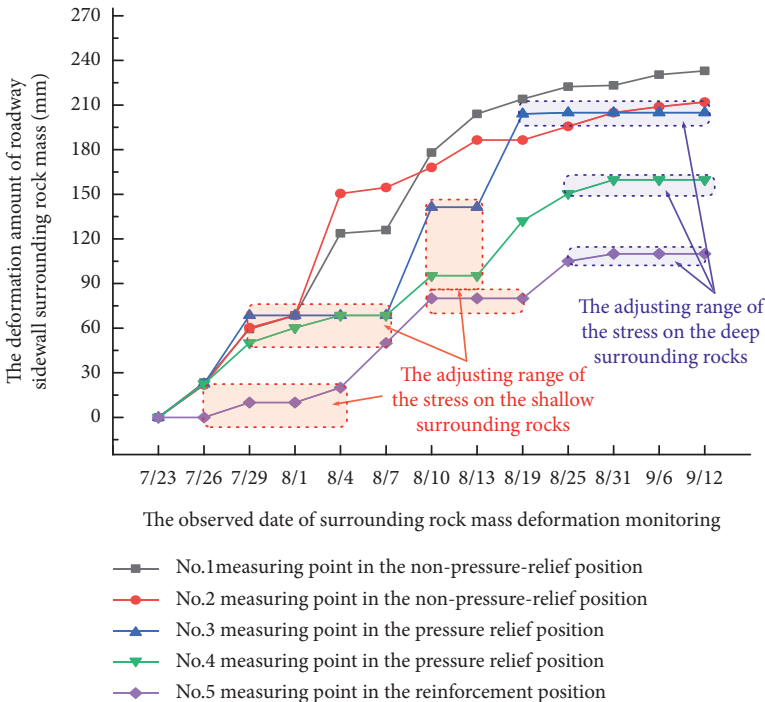

(a)

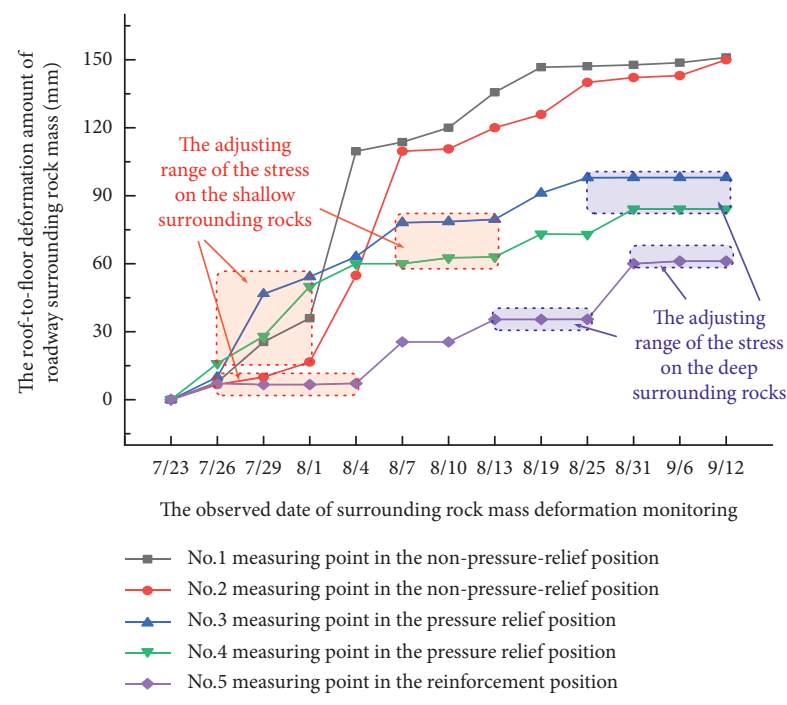

(b)

FIGURE 17: Deformation of surrounding rock mass: (a) convergence on both sides of roadway; (b) roof-to-floor convergence of roadway.

roadway rather than to the floor. The bottom supporting zone moves toward deep regions, and surrounding rock stress in the shallow plastic zone declines, thus preventing malignant expansion of the plastic zone and stabilizing the collapse form of broken surrounding rocks. This is consistent with the analysis results based on axis-changing theory.

\section{Case Study}

Based on the above research results, a case study on largediameter pore unloading technology in a great roadway of a coal mine in Henan Province was carried out. Monitoring data on convergence deformation of the roadway are shown in Figure 17.

It can be seen from Figure 17 that the roadway sides convergence and roof-to-floor convergence are increased significantly, reaching $230 \mathrm{~mm}$ and $152 \mathrm{~mm}$, respectively.
The total deformation on both sides of roadway was larger than the roof and floor deformations. In the nonconstructed and unloading section, the convergence deformation of roadway surrounding rocks lasted for a longer period, and the cumulative deformation was great. Deformations became stable gradually at about $33 \mathrm{~d}$, but they continued to increase. Due to unloading measures, convergence deformation of roadway surrounding rocks was intensified in early stage. The deformation rate was about $11.5 \mathrm{~mm} / \mathrm{d}$. The roof and floor deformation rate was about $7.8 \mathrm{~mm} / \mathrm{d}$, and the roof and floor deformation began to decrease gradually at $12 \sim 15 \mathrm{~d}$ until becoming stable. The first stability stage of deformation occurred at $6 \mathrm{~d}$. 9 days later, deformation presented the second progressive growths with the gradual collapse of unloading pores, accompanied by growths of roof-to-floor convergence. Unloading measures not only reduce surrounding rock deformations, but also accelerate stability of surrounding rocks. In the reinforcement section, 
total deformation was $110 \mathrm{~mm}$, and the total roof and floor deformations were $61 \mathrm{~mm}$. Surrounding rock deformation tends to be stable in about $5 \mathrm{~d}$. Reinforcement measures accelerate stability of surrounding rocks and reduce the deformation of roadway surrounding rocks effectively. Moreover, reinforcing both sides of roadway can lower roofto-floor convergence effectively, indicating that reinforcement can promote formation of a stable " $\Omega$-shaped" bearing structure.

\section{Conclusions}

This study summarizes characteristics and bearing structures of roadway surrounding rocks based on stress control through theoretical analysis, numerical simulation, and engineering measurement. Some major conclusions could be drawn:

(1) To address the difficult maintenance of high-stress roadway, bearing structural stability forms are analyzed from the perspective of mechanical properties of roadway surrounding rocks, surrounding rock stress distribution characteristics, and mechanical bearing mechanism of bearing structures by using the axis-changing theory. It is suggested that unloading and reinforcement measures are adopted to improve the stress distribution state and bearing structural adjustment of surrounding rocks, and the axial ratio of equivalent bearing structural forms of surrounding rocks is optimized. A rock postpeak strain softening and dilatation model was introduced to investigate mechanical characteristics of surrounding rock mass in the rupture residual zone and plastic softening zone in a roadway.

(2) Based on theoretical analysis, unloading measures can reduce volume expansion of surrounding rocks caused by postpeak dilatation and inhibit growth of convergence deformation of roadway caused by harmful hulking deformation. Reinforcement measures can improve postpeak mechanical properties, increase bearing capacity of surrounding rocks, improve the stress distribution, and prevent malignant expansion of the surrounding rock plastic zone.

(3) Influences of unloading and reinforcement construction on stress path and mechanical properties of rock unit model are analyzed by combining the full stress-strain curves of rocks. Furthermore, influences of unloading and reinforcement measures on surrounding rock stress state as well as influences of rock failure development on bearing structure of surrounding rocks are analyzed.

(4) The numerical simulation shows that the unloading measures optimize the axial ratio of the roadway excavation space, while reinforcement measures promote the formation of a " $\Omega$-shaped" bearing structure on the surrounding rocks. Stress on the roof transfers to deep regions on both sides of roadway rather than to the floor, and the bottom bearing zones move to deep regions. Besides, shallow surrounding rock stress in the plastic zone declines, which prevents malignant expansion of the plastic zone and stabilizes the collapse form of broken surrounding rocks. These conform to analysis results based on the axis-changing theory.

\section{Data Availability}

The data used to support the findings of this study are included in the article.

\section{Conflicts of Interest}

The authors declare no conflicts of interest.

\section{Acknowledgments}

This work was supported by the National Key Research and Development Project of China (2017YFC0603003), National Natural Science Foundation of China (51804119, 51974009, 51974010, 51674008, and 51774008), National Natural Science Youth Fund (52004006), Key Research and Development Program of Anhui Province (201904a07020010), Leading Talent Project of Anhui "Special Support Program," Anhui Provincial Academic and Technology Leaders Research Activities Funding (2018D187), Excellence Talent Training Program of High School (gxbjZD2016051), and Talent Fund of AUST (13200013).

\section{References}

[1] C. Hou, X. Wang, J. bai, N. Meng, and W. Wu, "Basic theory and technology study of stability control for surrounding rock in deep roadway," Journal of China University of Mining and Technology, vol. 50, no. 1, pp. 1-12, 2021.

[2] C. Sun, X. Hui, and Q. Zhang, "Study on the post peak strain softening behavior of mudstone and the interaction between surrounding rock and supporting structure," Journal of China University of Mining and Technology, vol. 45, no. 2, pp. 254-260, 2016.

[3] X. Zhang, G. Zhao, and X. Meng, "Elastoplastic solution for surrounding rock of circular roadway based on D-P criterion by considering post-peak strain softening and dilatancy," Journal of Mining and Safety Engineering, vol. 30, no. 6, pp. 903-916, 2013.

[4] J. Pan, Z. Gao, and F. Ren, "Effect of strength criteria on surrounding rock of circular roadway considering strain softening and dilatancy," Journal of China Coal Society, vol. 43, no. 12, pp. 3293-3301, 2018.

[5] Q. Wang, B. Jiang, R. Pan et al., "Failure mechanism of surrounding rock with high stress and confined concrete support system," International Journal of Rock Mechanics and Mining Sciences, vol. 102, no. 1, pp. 89-100, 2018.

[6] D. Qin, X. Wang, D. Zhang et al., "Study on surrounding rock-bearing structure and associated control mechanism of deep soft rock," Sustainability, vol. 11, no. 7, pp. 1-15, 2019.

[7] X. Yang, C. Liu, H. Sun et al., "Research on the deformation mechanism and directional blasting roof cutting control measures of a deep buried high-stress roadway," Shock and Vibration, vol. 2020, 14 pages, 2020. 
[8] W. Wang, Y. Zhu, S. Li et al., "The principle of stability control of surrounding rock-bearing structures in high stress soft rock roadways," Journal of Coal Science and Engineering, vol. 15, no. 1, pp. 24-27, 2019.

[9] R. Peng, Z. Ouyang, Q. Zhao et al., "Studies on support techniques for roadway bearing structure features under different geo-pressures," Arabian Journal of Geosciences, vol. 13, no. 1, pp. 1178-1190, 2020.

[10] G. Zhang and F. He, "Deformation failure mechanism of high stress deep soft roadway and its control," Journal of Mining and Safety Engineering, vol. 32, no. 4, pp. 571-577, 2015.

[11] F. Dong, H. Song, Z. Guo, S. Lu, and S. Liang, "Roadway support theory based on broken rock zone," Journal of China Coal Society, vol. 19, no. 1, pp. 22-32, 1994.

[12] H. JIng, Q. Meng, J. Zhu, B. Meng, and L. Yu, "Theoretical and technical progress of stability control of broken rock zone of deep roadway surrounding rock," Journal of Mining and Safety Engineering, vol. 37, no. 3, pp. 429-442, 2020.

[13] H. Kang, "Bearing ring analysis of roadway surrounding rock," Rock and Soil Mechanics, vol. 17, no. 4, pp. 84-89, 1996.

[14] H. Kang, "Seventy years development and prospects of strata control technology for coal mine roadways in China," Chinese Journal of Rock Mechanics and Engineering, vol. 40, no. X, pp. 1-30, 2021.

[15] H. Kang, P. Jiang, B. Huang et al., "Roadway strata control technology by means of bolting-modification-destressing in synergy in $1000 \mathrm{~m}$ deep coal mines," Journal of China Coal Society, vol. 45, no. 3, pp. 845-864, 2020.

[16] X. Yu and D. Qiao, "Theory of axial variation and three rules of axial ratio for stabilizing country rock," Nonferrous Metals, vol. 33, no. 3, pp. 8-15, 1981.

[17] $\mathrm{X} . \mathrm{Yu}$, "On the theory of axial variation and basic rules of deformation and fracture of rocks surrounding underground excavations," Uranium Mining and Metallurgy, vol. 1, no. 1, pp. 8-17, 1982.

[18] X. Yang, S. He, and T. Gao, "Research about parameter of unloading by hole drilling in underground roadway," Rock and Soil Mechanics, vol. 16, no. 1, pp. 46-53, 1995.

[19] S. Li, W. Wang, and C. Pan, "Numerical analysis on support structure of rock around deep roadway," Chinese Journal of Geotechnical Engineering, vol. 28, no. 3, pp. 377-381, 2006.

[20] Z. Fang, "The features of tensile and compressive and the supporting principle of the primary and secondary bearing zone," The Current Conditions and Prospects on the Soft Engineering Technique, Coal Industry Publishing House, Beijing, China, 1999.

[21] G. Hou, "Interaction mechanism between surrounding rock and support based on spatial effect of excavation face," Chinese Journal of Rock Mechanics and Engineering, vol. 30, no. S1, pp. 2871-2877, 2011.

[22] J. Zuo, Y. Shi, D. Liu, Y. Sun, and C. Yan, “The equivalent ellipse model and simulation analysis of destressing by cutting groove in deep soft rock roadway," Journal of China University of Mining and Technology, vol. 48, no. 1, pp. 1-11, 2019.

[23] G. Zhao, X. Zhang, C. Wang, and X. Meng, "Mechanical analysis and numerical simulation for deep and shallow bearing structures of soft and broken roadway surrounding rock," Journal of China Coal Society, vol. 41, no. 7, pp. 1632-1642, 2016.

[24] J. Sun, "Rock rheological mechanics and its advance in engineering applications," Chinese Journal of Rock Mechanics and Engineering, vol. 26, no. 6, pp. 1081-1106, 2007. 